\title{
What elite men's collegiate tennis coaches look for in recruits and how they assess preferred player characteristics
}

\author{
Brandyn H. Fisher
}

Follow this and additional works at: https://researchrepository.wvu.edu/etd

\section{Recommended Citation}

Fisher, Brandyn H., "What elite men's collegiate tennis coaches look for in recruits and how they assess preferred player characteristics" (2015). Graduate Theses, Dissertations, and Problem Reports. 5601. https://researchrepository.wvu.edu/etd/5601

This Dissertation is protected by copyright and/or related rights. It has been brought to you by the The Research Repository @ WVU with permission from the rights-holder(s). You are free to use this Dissertation in any way that is permitted by the copyright and related rights legislation that applies to your use. For other uses you must obtain permission from the rights-holder(s) directly, unless additional rights are indicated by a Creative Commons license in the record and/ or on the work itself. This Dissertation has been accepted for inclusion in WVU Graduate Theses, Dissertations, and Problem Reports collection by an authorized administrator of The Research Repository @ WVU. For more information, please contact researchrepository@mail.wvu.edu. 
What Elite Men's Collegiate Tennis Coaches Look for in Recruits and How They Assess Preferred Player Characteristics

Brandyn H. Fisher

West Virginia University

Dissertation submitted to

The College of Physical Activity and Sport Sciences

at West Virginia University

in partial fulfillment of the requirements for the degree of

Doctorate of Philosophy

With an Emphasis In

Sport and Exercise Psychology

Edward Etzel, Ed. D. Chair

Kristen Dieffenbach, Ph.D.

Ryan Flett, Ph.D.

Ed Jacobs, Ph.D.

Jack Watson, Ph.D.

Morgantown, WV

April, 2015 


\begin{abstract}
What Elite Men's Collegiate Tennis Coaches Look for in Recruits and How They Assess Preferred Player Characteristics
\end{abstract}

Brandyn H. Fisher

Understanding what characteristics college tennis coaches look for, and how they evaluate these skills may provide beneficial information related to the recruiting process at the collegiate level. Currently, limited research exists concerning how college tennis coaches evaluate a recruit's intangible characteristics and what specific characteristics they look for. Some authors have suggested that coaches highly value intangible characteristics, such as character and leadership ability, and that these skills are believed to be necessary for success at the collegiate level (Flett, Paule, \& Schneider, 2010). However, little is known about the exact processes coaches use to evaluate intangible skills, nor which attributes are viewed as important. Therefore, the purposes of this study were to identify the characteristics that successful NCAA Division I men's tennis coaches look for and to determine how they evaluate these skills. Modified interpretive analysis was utilized to analyze the data (Hatch, 2002), from which two primary themes emerged: what characteristics coaches look for in recruits and how coaches assess a recruit's characteristics. These themes, along with relevant subthemes are discussed in depth and connections are made to existing literature.

Keywords: Intangible characteristics, evaluation methods, college recruiting 


\section{Table of Contents}

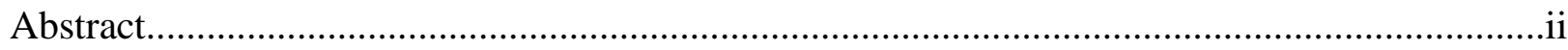

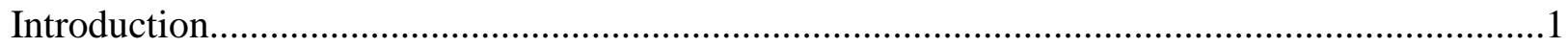

The Role of Intangible Characteristics in Recruiting..................................................2

Assessing Intangible Characteristics..............................................................

Making Recruiting Decisions: The Role of Intuition................................................5

Talent Selection Processes: Connecting Business Practices to College Recruiting............7

Need for Further Research.............................................................................

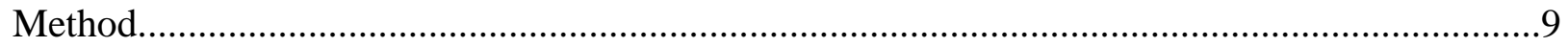

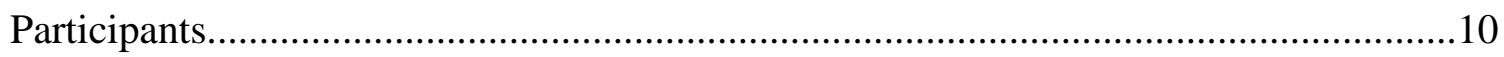

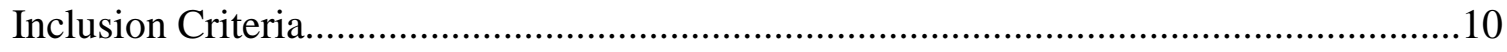

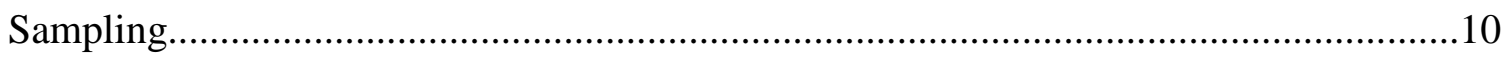

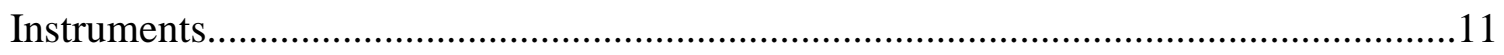

Procedure

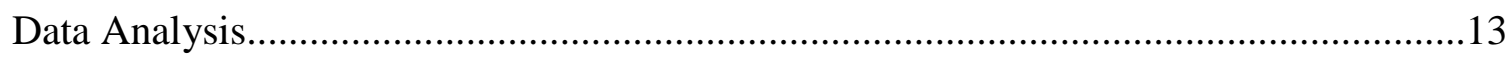

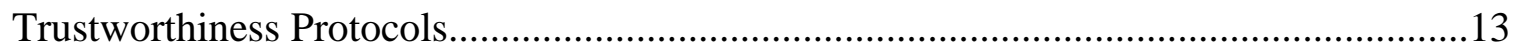

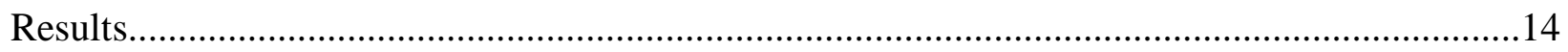

What characteristics coaches look for in recruits..................................................14

Intangible psychological characteristics..................................................15

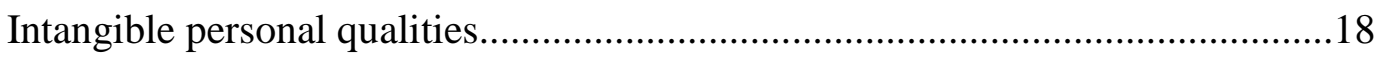

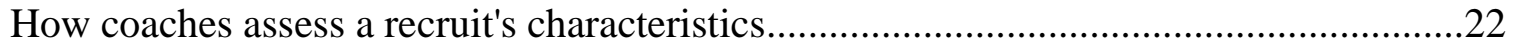

Relying on information from other sources.............................................23

Specific methods of evaluating characteristics............................................26

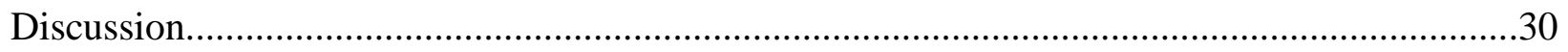


Characteristics college tennis coaches look for in recruits.........................................31

How college tennis coaches evaluate a recruit's characteristics...................................33

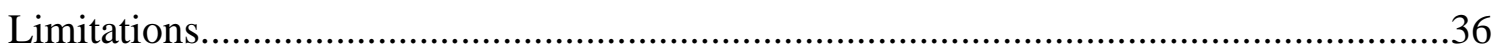

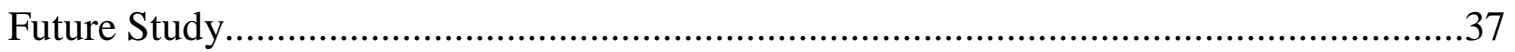

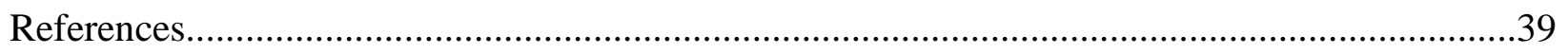

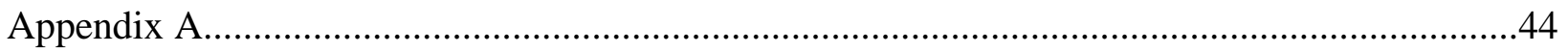

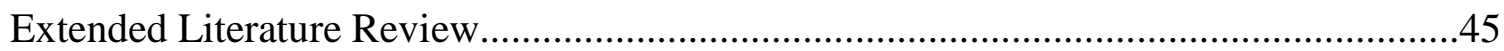

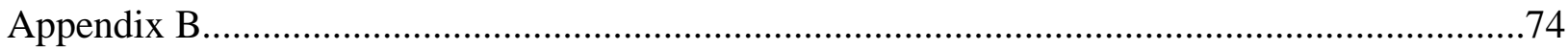

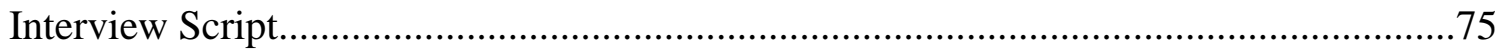

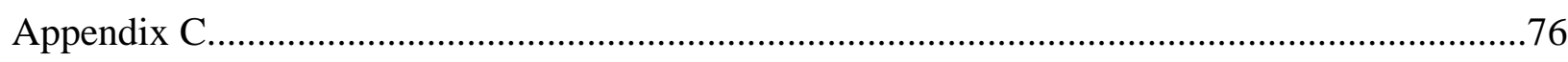

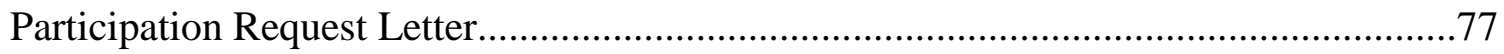

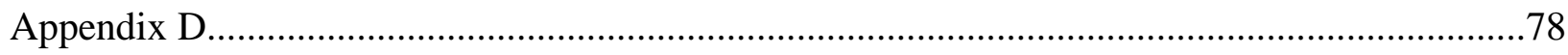

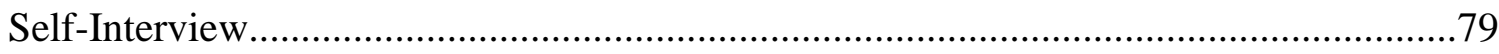

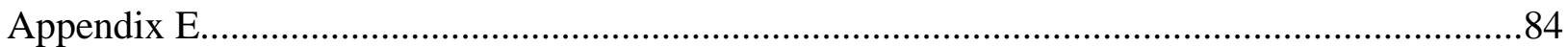

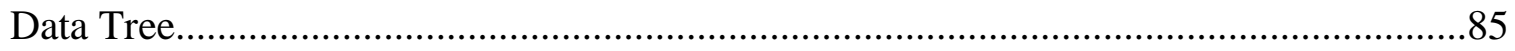




\section{What Elite Men's Collegiate Tennis Coaches Look for in Recruits and How They Assess Preferred Player Characteristics}

Collegiate sport in 2015 is very competitive. Many colleges and universities stand to profit from successful programs. Whether it is helping to increase student-body enrollment, enhance the quality of applicants, or overall financial gain due to athletic success, collegiate sporting programs have the potential to positively impact universities and colleges on a number of levels (Warren, 1997). And while successful revenue-producing sports like football can produce financial gain and increased enrollment, other successful teams like men's tennis contribute in other ways, such as earning points towards the Directors' Cup or the Capital One Cup. These organizations annually recognize the best overall college athletics programs in the country using the collective achievement of each team on campus, not just the revenueproducing sports. Therefore, colleges and universities stand to gain something more than just financial profit; they also stand to gain national prestige for having overall success in athletics.

A major contributing factor to a program's success is the ability of its coach to identify and recruit athletes who have the talent and ability to excel. More specifically, having reliable methods for detecting a recruit's abilities and making accurate personnel decisions would appear to be vital components of a coach's athletics program. Effective talent assessment methods, along with many other factors such as quality coaching, good facilities, and well-organized and conducted training, likely lead to future success whereas ineffective recruiting would seem to have a negative impact (Abbott \& Collins, 2004; Warren, 1997).

Despite the usefulness of anecdotal, professional practice-based knowledge, there exists limited empirical evidence concerning what skills college coaches look for and how they assess these attributes. While many authors have identified various psychological components that are 
related to athletic success (Abbott \& Collins, 2004; Elferink-Gemser, Visscher, \& Lemmink, 2007), it is uncertain if college coaches consider a recruit's psychological characteristics and personal qualities when assessing the athlete's abilities, and if they do, how they assess these skills. Although at least one study has highlighted the importance of psychological characteristics and personal qualities in recruiting at the collegiate level (Flett, Gould, Paule, \& Schneider, 2010), it remains unclear if these attributes influence a coaches' decision-making based on his or her perceptions of a recruit's characteristics and how these attributes are evaluated to begin with. If college coaches do look for psychological attributes and other personal qualities in recruits, it is unclear how these skills are evaluated and why these characteristics are desired. Therefore, additional research seems warranted to further understand what characteristics college coaches look for in recruits and the evaluative methods used to determine these skills.

\section{The Role of Intangible Characteristics in Recruiting}

While research is limited in the realm of recruiting and the specific processes used to identify and evaluate characteristics necessary for success at the collegiate level, some researchers emphasized the need to study the role of intangible psychosocial skills at this level. Flett et al., (2010) addressed a similar research question to the current study; that is, what role do factors, such as a person's psychological intangibles and perceived character, play in recruiting at the collegiate level and how are they assessed? Their study addressed the role of character and life skill development in the recruiting process while attending to the relatively unknown aspects of recruiting, such as a coach's perceptions of sought-after personal attributes and how these might be measured. These researchers interviewed 10 Canadian university coaches from several male and female sports, including football, basketball, hockey, volleyball, and wrestling. They 
found that those coaches were able to describe necessary intangibles needed at the collegiate level, such as maturity and work ethic. Further, not only did the coaches highly value athletes with these perceived attributes, but there were specific strategies used to assess these intangible skills. Coaches were able to describe methods they used to identify these attributes to include relying on information from a personal network of other coaches or teachers, as well as using their current players to assist in the assessment efforts. Although coaches had methods of evaluating intangible characteristics in recruits, several of the participants explained that these methods were not that reliable in differentiating successful players from less-successful players. This suggests that further research in this area is warranted to provide a clearer picture of the methods coaches might want to employ to more consistently identify intangible attributes and psychological attributes useful to effective recruiting.

In a related study, Kavekar and Ford (2010) surveyed 50 of the most successful coaches in NCAA Division I softball to determine coaches' recruitment criteria and methods. This particular study considered a multitude of factors, such as the use of statistical data, recruiting timelines, and the measurement of tangible and intangible athlete factors. Respondents identified specific skill-sets that are most important, such as "being a team player," and "having a strong work ethic." Other highlighted responses were "character and values," as well as "having determination and desire." During the recruiting process, the top three variables considered when watching a recruit play or practice live were perceived athletic ability, attitude, and hustle. These findings offer a glimpse into some select recruiting methods used by collegiate coaches, as well as identify specific characteristics that coaches may look for during the recruitment process. While both the Flett, et al. (2010) and Kavekar and Ford (2010) studies provided further insight into the recruiting world related to what characteristics coaches look for in recruits and the 
methods they use to evaluate these skills, there exists a need to study these concepts in greater depth to better understand what characteristics college coaches look for in recruits and how they assess these skills.

\section{Assessing Intangible Characteristics}

Research focusing on psychological characteristics of athletes has been linked to the assumption that psychological attributes, such as the ability to focus, set and attain goals, recover from mistakes, and having a positive mindset, are essential to high-level sport performance. Accordingly, some researchers have centered their attention on determining the psychological characteristics that may predict successful performance (Camire \& Trudel, 2014; McNamara, Button, \& Collins, 2010). But how exactly do coaches evaluate intangible characteristics that translate to athletic success?

Christensen (2009) found that coaches use subjective methods to evaluate players' talents and abilities. Through in-depth interviews of eight national youth soccer coaches, Christensen found that the sampled coaches considered and looked for talent in three ways. First, they used a "practical sense," or an acquired system of preferences based on perceptions. This practical sense is experience-based and relates mostly to evaluating sport-specific skills that may separate one performer from another. Second, those coaches used a subjective classification system to differentiate a set of potential-based concepts, such as a perceived ability to learn and improve. Lastly, coaches reported using a socially constructed system of judgments when evaluating talent, which is based on a coach's "taste" stemming from his or her talent assessment methods. Other authors observed that coaches' evaluative methods and procedures are generally based on subjective feelings, intuition, and previous experience rather than a well-defined, objective 
process (Gilbert, \& Trudel, 2001; Jones, Armour, \& Potrac, 2002; Jones, Armour, \& Potrac, 2004; Saury, \& Durand, 1998).

In a study to investigate how youth soccer coaches conceptualize talent with the purpose of identifying players with potential for future success, Vrljic and Mallett (2008) found that coaches were able to identify specific skills they desire, and coaches' preferred method of evaluating talent was via live practice or game play scenarios, rather than skill-specific drills and tests. This is of particular relevance to this study, as it offers insight into how coaches assess skill and make judgments regarding talent. In addition to physical and technical talent, these authors found that coaches also looked for cognitive-perceptual skills (i.e., ability to read play) and personal qualities (i.e., desire to succeed, mentally tough, team player), which suggests there are objective and subjective methods in which they employ. However, further research is warranted to determine the subjective methods used by coaches, especially at the collegiate level.

\section{Making Recruiting Decisions: The Role of Intuition}

While certain researchers have identified the characteristics coaches look for in recruits and the processes coaches use to evaluate skills, others have focused more on the decisionmaking processes of expert coaches; in particular, how a coach comes to a conclusion based on the gathered information. Certain authors have identified the role of intuition in an expert's decision-making process and suggest that intuition is essentially the ability to recognize an answer based on information stored in memory (Simon, 1992). Similarly, St. Pierre and Smith (2014) viewed intuition as a "process that involves formal knowledge, keen perceptual abilities, and holistic recognition of patterns that have been drawn from memory" (p.39). It would appear that an individual's experience plays a role in developing intuition and that intuitive thoughts stem from ones prior knowledge in given situations. 
Davids and Meyers (1990) discussed the role of intuition in guiding a coach's actions in which they state, "as expertise grows, greater reliance is placed on intuitive feeling to guide performance" (p. 275). This suggests that expert coaches operate based on feel to guide their decision-making related to recruiting, and intuition becomes increasingly involved as a coach develops in his or her profession. It is feasible to think that college coaches utilize intuition in recruiting, in which experience likely plays a significant role in how coaches make personnel decisions. However, additional research is needed to understand these assumptions.

Other authors have suggested that experts process information in an intangible manner and their decision-making reflects this process, whereas novices concentrate on irrelevant information (Hinds, Patterson, \& Pfeffer, 2001). While these authors support the notion that intuition is based on one's experience and these experiences guide future action, others suggest that skilled individuals are typically unaware of the cues that influence them (Kahneman \& Klein, 2009). According to Vaughan (1979) intuition is, "Knowing without being able to explain how we know" (p.46). Therefore, are coaches aware of the cues that influence their decisionmaking? Are coaches able to explain how they go about evaluating a recruit's skills and how they use this information to guide their decision-making? Nash and Collins (2006) suggested that coaches rely greatly on tacit knowledge, or the experience gained from performing everyday actions, and decision-making processes of expert coaches become less-defined due to a lack of awareness behind why these decisions are being made. In a recruiting context, this would intimate that while expert coaches rely heavily on their own prior recruiting experiences, they do not have a good understanding of why they take this particular approach. While there is limited literature related to the decision-making processes coaches use at the collegiate level, there is an abundance of empirical and anecdotal evidence in business. 


\section{Talent Selection Processes: Connecting Business Practices to College Recruiting}

Many authors have highlighted the role that a company's tacit knowledge plays in the organization's ability to remain innovative and flexible (Eisenhardt, 1997; Leonard \& Sensiper, 1998). It would appear that experience plays a key role in talent selection and decision-making in business contexts, and organizations are actively and consistently engaged in finding methods of improving their manager's talent selection and decision-making prowess. It is through experience that a manager can make decisions more effectively and identify a decision's outcomes, thereby limiting a negative reaction (Klein \& Weick, 2000). But when it comes to selecting talent, what skills are individuals in decision-making roles looking for, and how do they assess candidates? Bennis and Toole (2000) discussed the importance of measuring a candidate's "soft qualities", such as leadership, integrity, and talent for creating other leaders. Further, these authors found anecdotal examples of the processes businesses use to assess a candidate's qualities, which mainly involved interviewing individuals who know the candidate in question and gathering as much information as possible to make an informed decision. In creating a more complete picture of a candidate, including his or her personal qualities, those in decision-making roles are better equipped to identify individuals who match the company's needs.

In their review of how multinational organizations build and sustain their talent pipelines, Stahl and colleagues (2007) found that these companies generally followed processes that would lead to hiring candidates who were an internal fit (i.e., consistent values with those of the company), a cultural fit (i.e., alignment with the corporate culture), and a strategic fit (i.e., alignment with the goals of the company). These authors found that leading multinational companies used a variety of talent selection procedures, including developing ties with universities, and utilized assessment methods that identified a recruit's characteristics and 
personal values to determine fit with the organization. Skills such as integrity, compassion, and leadership were highly valued and necessary for successful corporate integration. Also, it was found that companies attempted to identify individuals with leadership talent through multiple evaluation avenues, including the use of standardized assessments and interviewing the candidate's contacts.

Businesses often use various assessments in identifying and selecting talent, such as traitbased assessments, psychometric tests, and talent interviews. It is thought that these assessments adequately identify candidates who possess the types of skills companies covet, and therefore limit hiring errors and mistakes (Zapka, 2009). While organizations have the ability to administer personality tests and other psychometric tests, college coaches are more hesitant in using these information-gathering tools. While the NCAA allows coaches to assess a recruit's personality profile through administration of personality surveys, there is evidence to suggest that coaches are wary of administering these assessments for fear of losing out on a recruit because he or she will be turned off by the experience (Eisenberg, 2013). It is commonplace for HR personnel to administer assessments for potential employees, but there remains a gap between the usefulness of these tests and the practical application in a college recruiting environment.

These studies offer a glimpse into the realm of talent selection in the business world and identify specific methods companies use to select candidates and which skills are deemed important. Corporations cast a wide net and exhaust several avenues when looking for talented candidates who possess skills that translate into organizational success. Human resource managers are faced with the challenging task of narrowing the applicant pool, and as a result, they utilize all means necessary to identify candidates for further evaluation. College coaches 
might stand to benefit from employing similar practices to those of business leaders who are charged with identifying and selecting talented individuals, but additional research is warranted to determine how these methods might benefit and be used by college coaches.

\section{Need for Further Research}

Collegiate recruiting methods, specifically what coaches look for and how they go about evaluating athletes' abilities, are relatively unknown processes. This could be in part due to the ever-increasing competitiveness in sport and the desire of coaches to keep their methods and processes a trade secret. Or, it could simply be that no one has yet to ask coaches these types of questions. While one study exists on the topic (Flett et al., 2010), there is limited knowledge related to what characteristics coaches look for and how these skills are evaluated. Flett and colleagues (2010) identified college coaches' processes in recruiting athletes based on his or her intangible, psychosocial skills, and while this particular study offers a glimpse into what college coaches look for in recruits and how they assess these athletes, additional research is warranted to truly understand these processes. There is a need to examine these concepts further to help identify the evaluative methods college coaches use, as well as determine what characteristics they are looking for in recruits. For instance, how do intangible factors, such as psychological characteristics and personal character, influence college coaches' perceptions of recruits? What specific characteristics do coaches look for and how do they evaluate these attributes? Answers to these types of questions are needed to shed light on a relatively unknown area of a college coach's profession. In view of the foregoing, the purposes of this research investigation were to: 1) identify the characteristics that successful men's college tennis coaches look for in recruits, and 2) examine how elite men's tennis coaches evaluate a recruit's characteristics.

\section{Method}




\section{Participants}

The participants in this study were eight $(N=8)$ National Collegiate Athletic Association (NCAA) Division I collegiate men's tennis coaches $\left(M_{\mathrm{age}}=45.3\right.$ years, age range: $41-58$ years $)$. Participants from the Southeastern Conference $(n=3)$, Atlantic Coast Conference $(n=2)$, Big 12 Conference $(n=2)$, and Pac-10 Conference $(n=1)$ were represented in this study, and combined for 130 years of experience at their current institutions $(M=10.5$ years, $S D=9.3$, range: 5-33 years experience). Collectively, participants had 2,015 NCAA DI wins $(M=251.8, S D=153.2$, range: $125-825$ wins), 15 NCAA DI championships, and a combined $78 \%$ winning percentage in their current coaching positions $(M=78.7 \%, S D=5.8 \%$, range in winning percentage: $71-86 \%)$. Participants were identified by compiling a detailed list of all NCAA Division I men's tennis coaches and their respective winning percentages and length of tenure at their current institutions. Once compiled, only those coaches who met the inclusion criteria were contacted by the principle investigator to request voluntary participation.

Inclusion criteria. To be eligible to participate in this study, coaches had to meet the following three criteria: 1) currently coaching at a Division I men's tennis program; 2) coaching at current institution for a minimum of five years; and 3) have a winning percentage of at least $70 \%$ during coaching tenure.

Sampling. Criterion and purposive sampling were employed in this study (Patton, 2002). Criterion sampling refers to the manner in which the sample was chosen. In the current study, criterion sampling pertain to the fact that participants were limited to current coaches who had been coaching for at least five years at their current institutions and who have achieved a winning percentage of at least 70\%. Of the 266 Division I men's tennis programs, only 14 
coaches met the coaching length and success requirements, which represented approximately the top $5 \%$ of the entire coaching community.

Purposive sampling refers to intentionally focusing on a population as identified through specific inclusion criteria. The population identified, elite NCAA Division I men's tennis coaches, was involved in this study due to the principle investigator's experience within the sport of tennis and collegiate coaching. Additionally, it was anticipated that this population would produce data relevant to the proposed purposes research investigation.

\section{Instruments}

Interview protocol. An interview script was developed by the principle investigator and was modified by an expert in qualitative research in this study (see Appendix B). The interview protocol was developed by the primary investigator. The interview script included a series of open-ended questions related to intangible skills men's college tennis coaches look for in recruits and how coaches assess these abilities. Questions were developed based on previous empirical research (Kimbrough \& Copeland, n.d.; Stier \& Schneider, 2006), coach decision-making (Christensen, 2009; Nash, \& Collins, 2006) and anecdotal evidence (Conley, 2008; Kulina, 2009; Spoon, n.d.) related to recruiting.

Questions were asked in the same order for each participant in a semi-structured manner, which allowed the interviewees the opportunity to answer questions completely and in their own style. However, it was possible, given the nature of the interview process, that participants might answer more than one question within a response, or that the order of questions needed to vary in order to maintain a level of fluency during the interview. Interviews averaged 45 minutes in length, ranging from 40 minutes to 65 minutes, and produced 61 single-spaced pages of transcribed data. 


\section{Procedure}

Approval from the Institutional Review Board for the protection of Human Subjects (IRB) was obtained prior to the commencement of this study. This study employed a qualitative design using interactive interviews. Eligible tennis coaches were contacted by phone by the principle investigator to solicit interest in participating in the interview process. Coaches who expressed an interest in participating were given the opportunity to request an appropriate date and time for the interview to take place. Prior to the interview, coaches were provided with a letter stating the purposes of the research investigation, rationale for their involvement, and a statement pertaining to confidentiality of the information collected. Each participant read, signed and returned a consent form before the interview occurred.

\section{Data Analysis}

Upon completion of the interviews, recordings were transcribed verbatim by the primary researcher and the transcripts were shared with two other coders. Transcripts were coded in the order in which interviews were completed and memos were used to identify themes for further discussion. A modified interpretive analysis was utilized to guide the analysis of the data. The general format of interpretive analysis was used by reviewing the data in its entirety to gain a sense of its meaning, followed by using memos to identify impressions from the transcripts, and then categorizing codes into categories (Hatch, 2002). From the resulting categories, emergent themes were created and excerpts from the transcripts were used to exemplify the final codes and categories. Analysis produced five higher-order themes that supported the two general themes: Intangible characteristics coaches look for and how coaches evaluate such characteristics.

Triangulation. Data and investigator triangulation were utilized in the data analysis process to validate data and to minimize researcher biases. According to Denzin (1970), 
investigator triangulation entails the use of more than one researcher to gather and interpret data. Further, data triangulation is the use of multiple data sources to produce understanding of a topic. Data triangulation occurred through the use of interview data, in which eight separate collection points were established, as each participant was asked the same set of questions. Investigator triangulation occurred through the inclusion of two other researchers who independently examined and coded the data to provide a source for inter-rater reliability. Investigators convened periodically to compare coded data. During these meetings, discrepancies were discussed and addressed, and were solved by taking a majority vote to determine the outcome of the coding discrepancy.

Coders. At the time of the interviews, the primary researcher and interviewer was a fourth year doctoral student. This coder had taken a course in qualitative methods and was mentored by an expert in qualitative analysis. The second coder was a faculty member in a sport psychology doctoral program with an extensive background in qualitative research. The third coder was a second year Master's student in athletic coaching education with no prior training in qualitative methods. The coding team met on two occasions to review the coding process and provide training for the third coder who had no prior experience with this type of research. The training consisted of reviewing qualitative research methods and providing the third coder with examples of coded transcripts.

\section{Trustworthiness Protocols}

Bracketing interview. Prior to the interviews, the primary investigator partook in a bracketing interview in order to identify his own biases and assumptions. A bracketing interview is effective in disclosing the primary investigator's preconceptions of a study's aim prior to its commencement (Van Maanen, 1983). Additionally, the bracketing interview exposes the 
primary investigator's potential biases to increase awareness of how these biases may influence the investigator's interpretation of the results (Pollio, Henley, \& Thompson, 1997; Thomas \& Pollio, 2002).

Pilot interview. A pilot interview of one men's collegiate tennis coach was conducted prior to the interviews to give the primary investigator the opportunity to use the developed interview script, as well as make any alterations that were needed to clarify questions or to make the interview script more fluid and comprehensive. The subject was selected from the resulting list of coaches who met the criteria for inclusion in this study. The pilot interview was conducted via telephone by the primary investigator.

\section{Results}

The results have been organized in a manner to reflect the themes and subthemes that emerged from the data. Two central themes emerged: a) What characteristics coaches look for in recruits, and b) how coaches assess a recruit's characteristics. Several smaller categories of each subtheme were identified and will be discussed in further detail below, along with the relevant number of participants who spoke about them during the interview (see Appendix E).

\section{What characteristics coaches look for in recruits}

The first research question asked what characteristics do men's college tennis coaches look for in recruits? Coaches held specific opinions about characteristics they look for in recruits. However, they recognized that finding the "ideal" recruit was rare, and therefore they took the approach of finding players who possessed characteristics that were good for their programs. In looking for these types of recruits, coaches wanted players to have characteristics that were closely aligned with the team's culture and the coaches' own values. All of the coaches interviewed looked for and highly valued a recruit's intangible qualities, both as a player and as a 
person, and they described their opinions about what characteristics aligned with their programs and were necessary for success at the collegiate level. In essence, coaches said they looked for players who possessed a high level of tennis ability, high level academic functioning, and had a specific disposition and demeanor on and off the court. In the words of Coach 2, "The guy has to be a good student, has to be a great player, and you know, have the whole package." Two themes emerged for this category: a) intangible psychological characteristics and b) intangible personal qualities. All of the participants interviewed discussed the characteristics they looked for in recruits.

Intangible psychological characteristics. In the first theme, coaches provided their perceptions related to psychological characteristics and their importance in recruiting. All of the coaches identified intangible psychological characteristics that recruits needed to possess. These attributes were viewed as necessary for further recruitment. The psychological attributes coaches mentioned included: tennis IQ, poise under pressure, competitiveness, resiliency, confidence, and focus.

Tennis IQ. Six coaches explained the importance of the player's apparent knowledge of the game (i.e., strategy, tactics, momentum control, etc.) and knowing how to win using the range of skills he possessed. Coaches were looking for smart players who were able to emphasize strengths and hide weaknesses, while constantly thinking of ways to adapt and play at a high level throughout competition. Coach 4 stated, "I want smart players, players who, uh, figure out ways to win. Uhm, so we are looking for players that are adapting, that, uh, that are moving out of position and know how to maintain themselves on the court."

Poise under pressure. The importance of composure in the presence of pressure was evident throughout the coaches' responses. As Coach 6 commented, “. . . pressure either makes 
you $15 \%$ better or $15 \%$ worse." Having the ability to control one's emotions under pressure and to continue to perform at a high level in such situations was deemed highly valuable and necessary. The coaches discussed how the national prestige of their programs led to increased pressure and being part of this type of atmosphere in a team setting can break an untested player. This can be seen in Coach 7's response:

". . we need guys who are used to being successful and know how to handle the pressure and high expectations of a program like this ... I mean, guys are going to get beat up if they can't handle the pressure, because we have pressure on us all the time. We are ranked towards the top every year and we have a target on our backs because of the success we have already had, uh, you know, guys need to have thick skin and to be able to handle that pressure and the stress."

Coaches recognized the difficulty of assessing how junior players might handle pressure in a team-based collegiate setting, because junior tennis is predominantly an individual sport where players play for themselves. There are few opportunities for junior players to play as members of a team and deal with the associated demands, which some players may react differently to when competing individually. As Coach 2 stated, "You just don't know until you get them here and put them in that situation." Even though coaches said they understood the difficulties in gauging how a junior player's perceived poise may transfer to the college ranks, they nevertheless placed a large importance on being able to handle pressure and the stress of competition.

Competitiveness. Seven coaches emphasized the importance of players to appear to be competitive and have an intense desire to win. They reported that being competitive was not a teachable attribute, but rather was a part of the player's personal fiber. Essentially, coaches 
believed competitiveness is a trait, meaning a player loves to play across situations, not just when the stakes are high. As Coach 5 stated:

". . I I look for someone who just loves to compete. Uhm, someone who is a true competitor and not just a situational competitor. . someone who is a true competitor and I would define a true competitor as that embraces competition, uhm, regardless of who they are playing, and enjoys the opportunity to compete each time they step onto the court to play."

Resiliency. Seven coaches discussed the perceived value of resiliency and overcoming the various effects of adverse situations. Coaches' believed that players must be able to persevere through their struggles and use the lessons gleaned from challenges to get better. For example, Coach 8 stated, ". . .they have to bounce back relatively quickly. . the guys need to hit the pressure head on and constantly make those mental adjustments throughout the weeks and months and years of their career." Coach 4 expressed a similar sentiment; "They are always learning from their matches, but uh, when the match is over and the lessons are understood, they move from it and won't let it define where they go from there."

Confidence. Belief in one's ability and the way in which one acts on this belief was recognized as a consistently desirable trait by seven of the coaches interviewed. Being able to override the emotional challenges that players experience with self-assurance was seen as an important attribute to be successful at the elite collegiate level. Coaches discussed the link between confidence and having experience with winning at the junior level. As Coach 7 stated, "We want confident players, which comes from their previous successes and ability to excel at the junior levels." 
Similarly, coaches said that confident players are able to perform at high levels even in the face of considerable pressure and adversity. In recruiting, coaches assessed composure while observing player's behavior in match situations to gauge a player's confidence and ability to maintain skills under pressure. As Coach 4 posits; "I mean everybody gets nervous when they finish out a match, but, but some people play a point differently. You know, we're looking for somebody who is going to keep going for their shots in that situation rather than somebody who stalls."

Focus. A player's ability to stay present and engaged in training and competition was identified by six of the coaches interviewed. Engagement was seen as the ability to stay aware and limit external influences and distractions, and to be able to respond positively when those situations arise, while performing at a high level. Coach 8 explained, ". . .they are able to stay focused on key moments and know how to handle them. . a mentally tough player doesn't check out. . I guess you would say they are locked in and completely immersed in what they are doing." Coach 3 used a player's ability to stay focused as a determining factor in future recruitment; "You can be a great athlete but if you're not alert and you just kind of wander around out there, uh, you know, that will take you off my list right there no matter what."

Intangible personal qualities. The second theme described coaches' perceptions of a recruit's personal qualities. Participants believed that selected personal qualities offered valuable insight into how well a recruit would fit on the team and at the university. Additionally, a recruit's ability to fit on the team was perceived to influence the level of success the team could achieve, and either positively or negatively influence a coach's enjoyment of coaching. As a result, coaches looked for a recruit's personal qualities that would increase the coach's enjoyment of coaching and translate to on-court success of the team. The personal qualities coaches looked 
for were: attitude and coachability, leadership, hardworking/motivated, low-maintenance, maturity, academic ability, character/personality fit, and sense of civic duty.

Attitude and coachability. There was general consensus among coaches that players should possess a perceived readiness to learn as well as to be able to accept constructive criticism and feedback. Seven coaches discussed how the player's attitude and ability to receive coaching influenced their recruiting decisions. In the words of Coach 5:

"I really enjoy working with guys that uh, enjoy competition and want to learn tennis.

They are still students of the game and they, they want to get better and praise the opportunities to be coached and, and be in an environment where they can improve."

Coaches sought out players who they believed want to play a central role in their own development and who will work with the coaching staff, receiving direction and correction when needed. In a sense, players must be able to take criticism at face-value, understanding the need for coaches to motivate by using a variety of methods. As Coach 8 stated, "I am looking for guys who I believe are coachable. I think just about all coaches need to get guys who will listen, who will trust the coach to help get the best out of the players."

Leadership. Six of the coaches discussed the importance of players becoming and serving as leaders on the team positively impacting everyone around them. There was a general sense that players who have the perceived ability to lead were able to make others around them better by modeling a drive for high performance and not accepting anything but the team's best effort. As Coach 4 expressed, “... there are guys on my team that won't be satisfied, and maybe ever. You know, these are the guys that drive everyone. . . They propel us forward and won't allow the other guys to slack off, you know." 
It was clear that coaches valued players with perceived leadership potential because these players eventually serve as motivators for the entire team. Further, having likeminded individuals who want the same outcomes and are motivated by getting better adds to the effectiveness of the team. This was evidenced in a statement made by Coach 8; "I need guys who are of similar character and will push each other every day, so having guys who are willing to step up and be leaders is also important."

Hardworking/motivated. At the core of what coaches said they look for is a selfmotivated, hardworking individual who has a growth mindset (Dweck, 2006), whether it be on the court, in the classroom, or in personal relationships. Responses from seven of the coaches were filled with statements related to players who had excellent work ethics and who had an internal drive to get better. A prime example of this belief was offered by Coach 6 who stated:

"... You get the players to feel as though where they are now is not enough ... That desire for more, that hunger for more knowledge ... These guys need to have a sense that their better is always one step ahead of them, and they need to do whatever it takes to find it."

Coaches wanted players who do not need to be inspired, but rather bring the inspiration themselves, which in turn would motivate others to seek the same goal. In the words of Coach 2 , players need to have "a relentless pursuit of excellence."

Low maintenance. Six coaches wanted players who were low maintenance - that is, who did not need to be guided through matches from a tactical and emotional standpoint. Soughtafter players were identified as being independent and able to problem-solve on their own. Being low maintenance also was linked to doing well academically and being a good teammate. As Coach 1 stated, ". . that could be low maintenance on the court, academically, in practice ... 
you don't have to watch every point of his match and still know that you're going to get a base effort level. . .He doesn't need his hand held."

Maturity. Six coaches looked for an athlete's perceived maturity level. This was characterized by players seen as having a sense of what they want to accomplish and who they are as a young person. As Coach 7 put it directly, "We want mature players who know who they are as people and know what they want to achieve with their tennis." Coaches were not looking for players who were unsure of what they wanted in their collegiate experience, or who did not have a good understanding of their strengths and weaknesses as a person and a player. This thought was best illustrated by Coach 5, who wanted players who were ". . Extremely stable and well put together. It would be someone who really knows themselves and has both feet planted on the ground at all times."

Academic ability. Seven coaches explicitly expressed the value and importance placed on academic achievement and made parallels between the skills needed to be successful on the court and in the classroom. As Coach 4 stated, "It takes discipline, hard work, if not long nights to pull out the books and do it. Uh, you know, it's those guys who do exceptionally well in school who have a tendency to do well on the tennis court." Coaches used academic accomplishment as an indicator of how well players might handle aspects of collegiate athletics, in particular the balancing act of being successful in both endeavors. As articulated by Coach 6, ". . They must be able to balance the academic success with the tennis stuff, then they are probably going to do well here as well."

Character/personality fit. Ensuring that a recruit's perceived personality and character would likely "fit" into the overall team dynamic was deemed essential by seven of the coaches interviewed. Perceived fit, or how a recruit's attributes would mesh with the team culture, 
influenced the coaches to the degree of likely altering their recruiting decisions due to mismatches between the team and prospect. This was best illustrated in Coach 8's response:

"Character is equally important to us. Our recruits have to fit that standard and if they don't we make note of it ... They don't get in if we see something that shows they don't have those necessary character pieces."

Sense of civic duty. Making contributions on the court and to the team as a whole were valuable qualities coaches looked for. Furthermore, there was also a general expressed belief in being community-oriented and providing service to others outside of the team and university (e.g., a history of participation in grass roots efforts to grow tennis, Habitat for Humanity). Six coaches discussed the value they placed on players who made contributions to the community, stating that community service was an indicator of a recruit's character. Coach 2 explained,

"They're interested in going out and doing things for the community. It's just being a good guy and just doing what's right, doing things that aren't necessary, things you would like done for yourself." Coach 3 expressed a similar sentiment; ". . That's exactly what we want, the guy to be better and to have contributed in the matches, but also in the classroom and community."

\section{How coaches assess a recruit's characteristics}

The second research question asked how do men's college tennis coaches assess a recruit's characteristics. All of the participants discussed how they used various evaluative methods that were available to them and were in compliance with NCAA recruiting rules. The main avenue of assessment fell in line with traditional recruiting methods, in which a coach evaluates a recruit during competition and creates an opinion of his abilities based on those observations. While personal observations certainly played a key role in how coaches assess a recruit's characteristics, coaches employed additional methods in an effort to more completely 
understand how a player might translate from junior tennis to collegiate tennis. As Coach 4 stated, "My opinion matters, but it is not the only one. Hearing from someone that I trust, hey this guy is going to be great in college because of $\mathrm{X}, \mathrm{Y}$, and $\mathrm{Z}$, and that matches what I'm seeing then I know it's right." Two themes emerged for this category: a) relying on information from other sources and b) specific methods of evaluating characteristics. Seven coaches also revealed how they relied on information from other sources and eight coaches discussed their specific methods of evaluating recruits' characteristics.

Relying on information from other sources. When evaluating recruits, all of the coaches discussed the importance of making informed decisions so as to limit making errors in judgment and attempting to limit overall risk. Acceptance of risk takes on the potential for undesirable outcomes, which could negatively impact team dynamics and coaching enjoyment. To further limit risk, coaches relied heavily on information gathered from other sources to develop a complete picture of potential recruits. The categories that emerged from this theme were: a) current and former players and b) personal network outside the team and university.

Current and former players. Seven coaches described a reliance on current and former players' perspectives and opinions related to the recruitment of prospects. Participants generally believed that their current and former players, who possess an intimate knowledge of the program's goals and direction, would provide a unique and candid perspective, one that is more directed at ensuring that a recruit would fit into the vision set forth by the coaching staff. Coach 6 stated, "Well, the best people to rely on are the players in the program now. The next would be former players, some of the guys who have been in our program and played for me with a clear understanding of what we are doing here." 
By soliciting their own players' opinions, coaches added important pieces of information about recruits (e.g., a player's true nature, work ethic) to get a better view of the overall profile. There was a general feeling among the coaches that their players' evaluations offered a more personal account of the recruit in question, mainly related to the prospective player's personality and demeanor on and off the court. Coach 7 stated:

"You know, uhm, our biggest recruiters are our own players. These are the guys who know these players inside and out, who uh, you know, have played and competed with and against in the juniors. When one of my guys tells me, coach, this guy is a pain in the ass and a lot of people don't like him, I take that seriously. I can get a good sense of how they compete, how they are liked by other players, and how hard they work, and what they like to do on the court."

The coaches believed that their current players offered a unique perspective, which may differ from the coaches' assessments. The coaches acknowledged that current players needed to be biased to root out any pretenders and to protect the vision and direction of the program. As Coach 8 stated, "When guys are committed to the team and to each other, they uh, they won't want just anyone to come in and be a part of what we are making here." The ability to trust current and former players' evaluations permeated throughout the coaches' dialogue. In the words of Coach 1, “I knew I was, I was only gonna listen to someone’s evaluation of someone who played for me, that I completely and implicitly trusted and I knew had my back and I had their back."

Personal network outside of the team and university. In addition to their former and current players, coaches discussed the importance of utilizing their network of professional contacts, which included other college coaches, junior tennis coaches, and tennis industry 
representatives. Soliciting opinions from a coach's network lends itself to being as meticulous as possible in gathering the most reliable and complete information about a prospect. Further, coaches felt that their own opinions may be positively or negatively biased, and as a result they may be blinded to a recruit's assets or shortcomings. As Coach 1 stated:

"I didn't want to be going to look at the players and say this guy is good, or this guy is not good. I wanted to see his results and I wanted to know from somebody I trusted and that trusted me to say that, uh, this guy is okay, this guy is a good player."

It was evident that coaches often sought out other coaches' evaluations of recruits to produce a more detailed account of the player's abilities and talents, but a deep level of trust was needed to garner merit of this evaluation. Several of the coaches interviewed stated that without an established relationship, evaluations from others would not carry as much weight. The coaches felt that trusted contacts (i.e., college coaches, junior tennis coaches, recruiting consultants) had a good understanding of their program's goals and values, and as a result would be able to recommend for or against the further recruitment of certain players. As Coach 6 expressed, "I will talk to other college coaches who I know and they know me. . .I have met a lot of the really good junior coaches, and uhm, they can help out a lot. . Even industry reps can give you a clue about the player." Coach 7 took it even further stating:

"We do our homework and we talk to as many people as possible to get a real sense of what the guy is like. We have connections in a lot of places that we can trust who we know will be honest about a player's abilities."

Participants also relied on their network to help guide their decision-making process, largely because there were limited opportunities to see players compete and spend personal time with 
recruits. Athletic budgets for recruiting were limited and as a result, coaches valued the opinions and experiences of others in the tennis industry to help fill in the blanks.

Specific methods of evaluating characteristics. Participants identified their methods for evaluating recruits' intangible characteristics and personal qualities. Coaches described three primary methods of evaluating a recruit's characteristics: 1) use of objective data, 2) personal observations of recruits at tournaments, and 3) personal interactions with recruits.

Use of objective data. All eight coaches expressed in detail the importance of a recruit's performance markers, namely rankings and results in tournaments at the national level (United States Tennis Association, Tennis Europe) and international level (International Tennis Federation, Association of Tennis Professionals). Coaches were mostly interested in a player's results and rankings at the highest levels of junior and professional play going back to his junior year in high school. Results and rankings were identified by utilizing recruiting websites such as www.tennisrecruiting.net or directly from the ITF or USTA websites. A player's results were perceived as being a reliable predictor of his potential for future success at the collegiate level, in addition to drawing attention as a possible recruit. Five coaches described using results as a guide for whom to observe and gather additional information. Coach 4 said, "I will take a player's results and that will give me a, a good idea of where they are, you know... I will use their results to see who I should go watch and find out more about."

Coaches were apparently swayed in favor for or against the initial recruitment of a player based on if he had won and done so consistently while in the junior or professional ranks. This was one of the first identified stages coaches utilized in the recruiting process - whittling down a larger pool of applicants to a more manageable number based primarily on a player's pedigree. If a player had shown limited success in higher level junior competition, they were unlikely to 
generate the headlines to attract attention from top college tennis programs. Coaches viewed success at the junior levels as a useful indicator of a player's ability to continue this success in college. As stated by Coach 1:

"If they haven't proven already their results, they're good enough to be here, I don't want to look at them. . . So I'm trying to recruit with the philosophy of the greatest predictor of success is past success."

Not surprisingly, coaches sought after the top players and used results as an initial measure to assist in narrowing down their search. According to the coaches interviewed, for a recruit to garner interest at the elite levels of men's college tennis, he would need to have a top 50 USTA national ranking, a top 100 ITF ranking, or have earned ATP points.

Each coach described how he used results to steer the direction of their recruiting whether or not they would pursue players more seriously. Seven coaches described the importance of results in terms of obtaining a deeper sense of the player as a competitor. They saw value in looking at match results to gauge prowess in winning and used this information to further predict how prior success might transfer to the collegiate level. Interestingly, a player's results were deemed important enough that coaches would overlook other deficiencies, such as a lack of physical size or technical proficiency. As stated by Coach 4:

"I'm going to look at results because I think results tell me what kind of competitor they are. You know, some guys just have a knack for winning, they like to win, and they have an ability to win. They don't necessarily look the prettiest, they don't necessarily look the most athletic, but they win a lot of matches."

When coaches evaluate players, the importance of a player's ability to triumph superseded his technical and physical qualities. In short, tactical success overshadows technical and physical 
ability. As Coach 1 stated, "I think that there are a lot of ways to win, and what I'm looking for is someone who has proven, that whatever skill they have, they can win doing it."

Personal observations of recruits at tournaments. Six coaches described the role of personal observations in their assessment of a recruit's characteristics. Coaches wanted to see players compete so they could gauge not only their technical and physical skills, but also get a sense of intangible psychological attributes (i.e., poise, resiliency, tennis IQ). As Coach 1 stated:

"When I go to these tournaments, you know, uh, the big ones especially, I always watch how a guy handles being watched, or if he loses the first set how will he come out in the second. I think it gives you a small bit of information, and uh, it might show something that is important about the guy's makeup."

These observations offered a glimpse into coaches' beliefs about such attributes, and also showed which abilities they often looked for when watching players compete. As Coach 8 stated, " I think you see a lot of a player's true self on and off the court by watching them compete when they don't know you are there watching." Taken together, coaches felt these observations assisted in creating an opinion of the player as a competitor, and as a person. As Coach 2 stated: "Uhm, I like to see how players respond to adversity. Yea that's a big one. You know, how they will act if things aren't going their way, or uh, maybe there's a bad call and things get heated. I mean, that is really important, that you see those things, because the email or phone call won't bring those things out. I really like seeing how guys are just before they go out or after they finish, uhm, that's good information too. If a kid is locked in and getting ready, I think that is a good indicator of how serious he is. Or you know, the guy just lost a tough match and how is he ten minutes later? Is he laughing and joking with his friends, or uh, does he take it to heart a little?" 
In addition to watching recruits compete, tournaments also provided coaches with an opportunity to observe recruits around their peers. Coaches described their efforts to assess if a recruit might fit within their team culture, and if the recruit had the necessary personal qualities on and off the court. As Coach 4 explained, "Team chemistry is an important part ... I think watching a guy around other players can give you some clues, that uh, that might tell you how well he's liked." A recruit's personal qualities on the court were also a determining factor in coaches' decisionmaking patterns. For instance, Coach 4 expressed, "If I see a guy cheat on the court that is it right there, uh, it doesn't matter how good he is, I'm not interested."

Personal interactions with recruits. Coaches also had a discerning eye when they interacted with recruits at tournaments, on official visits, and through phone calls, emails, and text messages. Given the recruiting and budget restrictions college coaches face, there are limited opportunities to evaluate a recruit's psychological attributes on the court, and his personal qualities off the court. Yet, these limited opportunities for interaction were useful in building an opinion of the recruit in question. Coach 4 stated, "I also just talk to the players, uhm, about other stuff, just to get an idea of what they are like. What else do they do? What is their family like? Uhm, so those are ways I can keep getting information." Communicating through email, phone, or text messaging were much more common ways of staying in touch with recruits and provided multiple instances for coaches to evaluate recruits in areas not necessarily seen on the court, such as how they communicate and if they are organized. Coach 8 stated:

"Well of course there is email and the phone calls. I mean, we get hundreds a week, and uh, my assistant is pretty busy. But those are certainly ways too, you can piece it together I guess. We have ruled out players before who were a pain in the ass with making a lot of calls, or just sending email after email. Look, these guys don't understand that what 
they put other there stays out there. If they send an email with the wrong name, or if they get the school wrong, it's really sloppy and says, I don't give a damn. There was this one kid who called me on accident, at 3AM. It was a mistake you know, but what does that tell you? It doesn't look good, just let me say it that way."

Taken together, coaches look for the complete person and player at the elite level of men's college tennis, which includes having attributes that transcend the tennis court. Coaches would ideally like a player to come in with a high level of maturity and drive to succeed at the collegiate level, while also being a proficient student and active member of society. Players who exhibit these attributes would appear ready to perform at a high level in an elite tennis program. Limited development effort would be needed to continue bringing the player along. But since these ideal individuals are not readily available, coaches must narrow down the available talent pool, which is based largely on results and rankings, prior experience and the opinions of a wide network of individuals with whom the coach has a relationship. Ultimately, coaches must balance the importance of physical talent (i.e., physical tools needed to play elite college tennis), psychological attributes (i.e., poise under pressure), and team culture (i.e., personality fit on the team) and make decisions based on their perceptions of these areas as a whole.

\section{Discussion}

The two purposes of this study were to: 1 ) identify the characteristics that a select sample of very successful men's college tennis coaches look for in recruits, and 2) examine how elite men's tennis coaches evaluate a recruit's characteristics. The results suggested that coaches valued both observable behavior, history of consistent success, and various intangible characteristics when evaluating a recruit's "fit" for their college tennis programs. Participants were generally similar when identifying desirable core prospect characteristics (e.g., poise under 
pressure, resiliency, and confidence). While there were several characteristics that coaches ideally wanted recruits to have, they also recognized that few candidates possessed them all. Thus, instead of recruiting for an "ideal fit" coaches took a more "best fit" approach. Further, it was found that coaches used a combination of personal observations, objective data (i.e., results, rankings) and information from other sources (i.e., other coaches, tennis industry representatives) to assess a prospective player's attributes and potential to succeed at the collegiate level.

\section{Characteristics college tennis coaches look for in recruits}

Results of the current study revealed that participants held certain shared beliefs related to perceived, intangible characteristics (i.e., psychological and personal qualities) that were needed to be successful at the elite collegiate level, and that coaches did take these skills into consideration during recruiting. Coaches valued such characteristics mainly due to the perception that they were necessary to succeed at the collegiate level, both on and off the court. While other factors also influenced coach's opinions about recruits (e.g., results, evaluations from other coaches), the coach's perceptions related to a recruit's intangible characteristics appeared to influence the direction a coach would take in pursuing a player further. Since coaches had limited opportunities to observe and evaluate these characteristics, they recognized a need to use multiple evaluations (e.g., observations during several tournaments) to create a complete picture of the player and how he might fit into their programs. Further, coaches went into a player-evaluation with a pre-conceived notion of what characteristics the player must have to warrant further recruitment.

The ability of coaches to identify important intangible characteristics has been supported in previous research as well (Flett, et al., 2010; Giacobbi, Whitney, Roper, \& Butryn, 2002; Vrljic \& Mallett, 2008). Coaches in the current study valued intangible psychological 
characteristics, such as resiliency and poise (see Appendix E), as well as intangible personal qualities, such as having a strong work-ethic and leadership ability (see Appendix E). These findings were similar to those of Flett et al., (2010), who found that coaches valued athletes with various intangible attributes (i.e., character, maturity, resiliency, work ethic) and employed strategies for identifying players who had these qualities over others. Participants identified intangible attributes that they looked for. These attributes are discussed in terms of psychological intangibles (i.e., competitiveness, tennis IQ, and poise) and personal qualities (i.e., maturity, academic ability, and work ethic).

Psychological intangibles. Certain psychological intangibles were viewed as necessary and essential for success. Coaches valued players who were seen as highly competitive and genuinely enjoyed competition, and also displayed perceived confidence while performing. Having the ability to bounce back after a loss or overcome adversity, as well as displaying poise under pressure were also intangibles that coaches looked for. By assessing a recruit's on-court psychological intangibles, coaches felt they could better predict how a player would react at the collegiate level, where skills like resiliency or poise were perceived as necessary for success. For example, while junior tennis is predominantly an individual sport, college tennis is a combination of both; a player may win his own match, but the team can still lose or vice versa. Incoming recruits must be able to handle the stresses of college tennis, such as playing up to 50 matches in a given season (singles and doubles), or playing in the deciding match of a 3-3 tie.

Intangible personal qualities. Participants also had clear opinions about the qualities that were necessary for success at the collegiate level, not just on the court, but in other areas as well, such as in the classroom and in the community. A recruit needed to have more than just a good game and strong physical talents; he must also possess certain individual qualities, such as 
academic prowess, maturity, and a commitment to community involvement. Furthermore, coaches looked for recruits who were low-maintenance and hardworking, had a good attitude and were coachable, and demonstrated leadership ability. In possessing these skills, coaches felt that players would positively acclimate to a team environment, add to the team's culture, and ultimately play a role in helping the team reach its goals.

While on-court skills were highly valued, a recruit's personal qualities and character were just as important in terms of how coaches perceived these players. If a player was very talented, but lacked personal qualities, coaches were faced with the decision of bringing in a player who might help them win, but could cause issues within the team setting, or go in a different direction. Based on the participants' experiences however, they were heavily influenced by the negative outcomes of recruiting a player simply because he was talented, and as a result, coaches placed more emphasis on a recruit's personal character.

\section{How college tennis coaches evaluate a recruit's characteristics}

While academic ability could be determined by looking at objective measures (i.e., college entrance test results, high school grade point averages), other factors, such as perceived leadership ability and maturity required a more subjective approach, which included relying on the opinions of others (i.e., college coaches and junior tennis coaches), as well as the interactions coaches had with recruits during recruiting trips or while at tournaments. Coaches also said they relied heavily upon information from external sources (e.g., third parties) and utilize this information when creating an opinion about a recruit.

Using objective data from competitions. When evaluating recruits, coaches started with studying objective data on recruits, such as rankings and results in competition. These objective measures were used to trim down a large recruiting list and to narrow the search for 
players who could meet or exceed the demands of an elite men's tennis program. Rankings and results gave coaches a baseline measurement of a recruit's success at the national, international, and even professional levels. For example, coaches put greater value on a player's participation and success at the professional level (i.e., ATP Challenger Tour) or international level (i.e., International Tennis Federation), followed by the national level (i.e., USTA events). Coaches used objective data points from the various competition levels to help guide their process, which ultimately led to a list of candidates for further evaluation. The players who made the initial cut were apparently perceived to have a better pedigree and the necessary physical and psychological abilities to perform at the elite collegiate level.

Detecting a recruit's characteristics. Tournament behavior, recruiting visit interactions, and electronic communication (i.e., email, text messaging) represented opportunities for coaches to detect and estimate some recruit personal qualities, such as character and maturity. Coaches in this study developed opinions and beliefs about a recruit's intangible skills throughout the course of multiple observations and interactions with these individuals. These beliefs were based upon a coach's extensive coaching and playing background. Because coaches played and coached at the collegiate level, they were better equipped to know which skills were necessary, as well as having the ability to recognize these skills in others. According to Salovey and Mayer (1990), the appraisal and understanding of emotion in others is a key component of emotional intelligence. By understanding the types of emotions and feelings in others, especially as it relates to sport performance, coaches are better equipped to predict future actions and behaviors in a given situation (Schneider, 2013). It would appear that coaches relied on their own emotional intelligence, specifically the ability to detect emotional regulation in others, to create beliefs about a recruit's intangible psychological and personal characteristics. From these 
beliefs, coaches developed more concrete opinions related to a recruit's ability to succeed in their programs and at their universities.

\section{Summary}

While coaches often think about their recruiting methods, they may not often share this information with others, and much less spend time discussing these approaches in detail. When given the chance, however, participants in the current study had a lot to say on the topics of what characteristics they look for and how they go about evaluating these skills and attributes. Participants appeared appreciative of having an opportunity to reflect on their methods and describe how they evaluated recruits. In doing so, coaches were able to explain how their methods have changed over the years and what factors tended to influence their current belief systems.

However, coaches expressed the general sentiment that they are continually looking for more accurate methods of identifying recruits who fit their programs. Six coaches made specific comments about how their current methods were not sufficient, such as this statement by Coach 8: "But I don't know if I have it yet. . .I want to keep progressing in how I do it here. . .I think we can get even better if we have a defined, uhm, maybe clearer direction of where to go." Coach 7 made a similar comment; "But at the same time, I sit here and think to myself, well what could be better about how I go about it? Because I think any coach will tell you that it, uh, the process is always changing and has to adapt." While there were no questions in the interview script related to how coaches might improve upon their methods, the participants voluntarily shared their desires to enhance these processes further. This suggests that a need exists for coaches to further refine their recruiting methods. 
Sport psychologists could add value in this process by assisting coaches in the development of a clear set of guidelines (i.e., what intangibles are most important) and methods (i.e., how to assess these skills) that reflect the coach's values, goals, and needs. Further, sport psychologists could assist coaches in creating recruiting methods (e.g., structured interviews, administration of sport-specific tests) that are linked to the coach's belief systems and goals for his program. In doing so, coaches might be more proficient in making clear recruiting evaluations and decisions that are guided by their own established set of principles and beliefs. As a result, coaches might be more focused on bringing in players who accurately fit these principles, which may ultimately lead to increased team success and the coach's personal enjoyment of coaching.

\section{Limitations}

This study had limitations that should be taken into consideration. First, the population of interest, elite Division I men's tennis coaches, represented a very small sample of select, voluntary participants whose thoughts may not be generalizable to other college tennis coaches or coaches from other sports. This specific population and sport were chosen based on the investigator's familiarity with tennis and collegiate tennis coaching, representing both a strength and limitation (i.e., interviewer bias). The objectivity of the study could have been further enhanced if a trained interviewer other than the principle investigator with less knowledge or experience with tennis had co-led the interviews. Also, half of the participants coached in the Southeastern Conference, which represents one of the top men's tennis conferences in the nation. Seven of the eight participants were currently coaching at a university located in the southern United States, and all eight participants coached at large universities. The sample of coaches in the current study is not diverse in terms of region, conference, and university size, and therefore 
it is difficult to determine if coaches from conferences elsewhere in the United States might share the same sentiments related to recruiting intangible characteristics and the methods used to evaluate these skills. For instance, college tennis in the northern conferences, and some western conferences, is played indoors for a majority of the season, whereas the southern conferences play outdoors year-round. It is unknown if coaches of indoor tennis programs might approach recruiting intangibles differently, given that indoor tennis is much faster (i.e., ball speed) and different skill-sets might be more desired than those expressed by coaches in the current study. Furthermore, most of the junior tournaments that college coaches attend are in the southern states, which might preclude coaches from northern or western states from observing recruits in person. As a result, different evaluation methods might be needed to gain insight into a recruit's characteristics.

\section{Future Study}

Given the limited amount of literature on the topic of what characteristics college coaches look for and how they evaluate these attributes, future research could follow a number of different pathways. Future research might focus on determining how college coaches learned to recruit and what influenced their current beliefs about intangible characteristics. This could provide a deeper understanding of how evaluative methods evolved and why certain characteristics are more valued than others.

Prospective research could also focus on what characteristics less-experienced or lesssuccessful tennis coaches look for in recruits, as well as their evaluation methods of these skills. It is possible that coaches with less experience or success may look for and value different skillsets than their more experienced and successful peers. Additionally, these individuals may employ different evaluation methods to assess a recruit's characteristics. Future research could 
also focus on how coaches from different divisions and conferences evaluate characteristics and what attributes are desired at these levels. Lastly, it would be useful to compare an incoming recruit's perceived value (i.e., psychological attributes, ability to succeed at collegiate level) with his subsequent college career in tennis and school (i.e., results, fit within team culture, academic success). Acquiring this information might help to determine how accurate coaches' evaluations are on the front end and provide further examination of how evaluation methods can be enhanced.

\section{Final Thoughts}

Interviews revealed that very successful, male collegiate tennis coaches were regularly evaluating and re-evaluating their recruiting strategies to formulate the most effective method of assessing prospects. These methods were crafted in an effort to limit recruiting errors and ultimately construct the best possible team. The interviews seemed to provide a valuable experience for the participants, in that they were able to think about and discuss their recruiting methods and reflect on a relatively private area of their work. To a degree, these reflections either justified a coach's assessment methods or exposed a need to create more effective

processes. Providing more opportunities to build upon these discussions could help coaches find better methods of evaluating during recruiting, as well as bridge the gap between research and applied work within the field of sport psychology. 


\section{References}

Abbott, A., \& Collins, D. (2004). Eliminating the dichotomy between theory and practice in talent identification and development: Considering the role of psychology. Journal of Sports Sciences, 22, 395-408.

Bennis, W. \& Toole, J. (2000). Don't hire the wrong CEO. Harvard Business Review, 78 (3), $171-176$.

Camire, M., \& Trudel, P. (2014). Helping youth sport coaches integrate psychological skills in their coaching practice. Qualitative Research in Sport, Exercise, and Health, 6 (4), $617-$ 634.

Christensen, M. K. (2009). "An eye for talent": Talent identification and the "practical sense" of top-level soccer coaches. Sociology of Sport Journal, 26, 365-382.

Conley, B. (2008, July). The importance of intangibles in recruiting. Retrieved April 2, 2009, from http://sports.espn.go.com/ncaa/recruiting/football/columns/story?columnist =conley_bill\&id=3499947.

Davids, K. \& Myers, C. (1990). The role of tacit knowledge in human skill performance. Journal of Human Movement Studies, 19, 273-288.

Denzin, N. K. (1970). The research act in sociology. Chicago: Aldine.

Dweck, C. (2006). Mindset: The new psychology of success. New York: Random House.

Eisenberg, J. (2013). Personality profiling is latest method coaches are using to evaluate potential recruits. Retrieved April 1, 2015 from http://sports.yahoo.com/blogs/ncaab-thedagger/personality-profiling-latest-method-coaches-using-evaluate-potential143500770.html 
Eisenhardt, K.M. (1997). Strategic decisions and all that jazz. Business Strategy Review, 8 (3), 13.

Elferink-Gemser, M. T., Visscher, C., Lemmink, K., \& Mulder, T. W., (2007). Multidimensional performance characteristics and standard of performance in talented youth field hockey players: A longitudinal study. Journal of Sports Sciences, 25, 481-489.

Flett, M. R., Gould, D. R., Paule, A. L., \& Schneider, R. P. (2010). How and why university coaches define, identify, and recruit 'intangibles'. International Journal of Coaching Science, $4,15-35$.

Giacobbi, P. R., Whitney, J., Roper, E., \& Butryn, T. (2002). College coaches' views about the development of successful athletes: A descriptive exploratory investigation. Journal of Sport Behavior, 25, 164-179.

Gilbert, W., \& Trudel, P. (2001). Learning to coach through experience: Reflection in model youth sport coaches. Journal of Teaching in Physical Education, 21, 16-34.

Hatch, A. (2002). Doing qualitative research in education settings. Albany, NY: State University of New York Press.

Hinds, P.J., Patterson, M., \& Pfeffer, J. (2001). Bothered by abstraction: The effect of expertise on knowledge transfer and subsequent novice performance. Journal of Applied Psychology (86), 1232-1243.

Jones, R. L., Armour, K. M., \& Potrac, P. (2002). Understanding the coaching process: A framework for social analysis. Quest, 54, 34-48.

Jones, R. L., Armour, K. M., \& Potrac, P. (2004). The cultures of coaching. London: Longman. Kahneman, D., \& Klein, G. (2009). Conditions for intuitive expertise. American Psychologist, $64(6), 515-526$. 
Kavekar, A. N., \& Ford, S. (2010). Investigation of recruiting criteria of leading NCAA division I softball coaches. Sport Journal, 13(2), 4.

Kimbrough, S., \& Copeland, J. (no date). The latest on collegiate recruiting: What qualities are important to coaches? Retrieved on April 2, 2009 from http://www.powerbasketball.com/ 061020.html

Klein, G., \& Weick, K.E. (2000). Decisions: making the right ones. Learning from the wrong ones. Across the Board, 6, 16-22.

Kulina, K. (2009). What college coaches look for: Your link to colleges. Retrieved on November 9, 2009 from http://baseballfactory.com/blog/2009/03/what-college-coaches-look-for-pt2.html

Leonard, D., \& Sensiper, S. (1998). The role of tacit knowledge in group innovation. California Management Review, 40 (3), 112-32.

McNamara, A., Button, A., \& Collins, D. (2010). The role of psychological characteristics in facilitating the pathway to elite performance part I: Identifying mental skills and behaviors. Sport Psychologist, 24 (1), 52-73.

Nash, C., \& Collins, D. (2006). Tacit knowledge in expert coaching: Science or art? Quest, 58, 465-477.

Patton, M. Q. (2002). Qualitative research \& evaluation methods ( $\left.{ }^{\mathrm{rd}} \mathrm{ed}.\right)$. Thousand Oaks, CA: Sage Publications, Inc.

Pollio, H., Henley, T., \& Thompson, C. (1997). The phenomenology of everyday life: Empirical investigations of human experience. New York: Cambridge University Press.

Salovey, P., \& Mayer, J. (1990). Emotional intelligence. Imagination, Cognition, and Personality, 9, 185-211. 
Saury, J., \& Durand, M. (1998). Practical knowledge in expert coaches: On site study of coaching in sailing. Research Quarterly for Exercise and Sport, 69, 254-266.

Schneider, R. C. (2013). Emotional intelligence: The overlooked component of sport leadership. The International Journal of Sport and Society, 3, 43-56.

Simon, H. A. (1992). What is an explanation of behavior? Psychological Science, 3, 150-161.

Spoon, R. (n.d.). College recruiting advice: What coaches want in recruits. Retrieved April 2, 2009 from http://www.winnersdepot.com/recruiting-advice/college-recruiters.htm.

Stahl, G., Bjorkman, I., Farndale, E., Morris, S., Paauwe, J., Stiles, P., Trevor, J., \& Wright, P. (2007). Global talent management: How leading multinationals build and sustain their talent pipeline. INSEAD, Fontainebleau, France.

Stier, W. F., \& Schneider, R. C. (2006). Preferred player characteristics and skills of Division I men's basketball coaches. The Sport Journal, 9, unpaginated.

St. Pierre, P., \& Smith, M. (2014). Intuition in coaching: It's not magic. Strategies: A Journal for Physical and Sport Educators, 27(2), 37-42.

Thompson, S. P., \& Pollio, H. R. (2002). Listening to patients: A phenomenological approach to nursing research and practice. New York: Springer.

Van Maanen, J. (1983). Qualitative methodology. London: Sage.

Vaughan, F. E. (1979). Awakening intuition. New York, NY: Doubleday.

Vrljic, K., \& Mallett, C. J. (2008). Coaching knowledge in identifying football talent. International Journal of Coaching Science, 3 (1).

Warren, W. (1997). Coaching and control: Controlling your program, your team, and your opponents. New Jersey: Prentice Hall. 
Zapka, P. (2009). Characteristics of effective leadership: Talent selection. Retrieved April 2, 2015 from https://www.wjmassoc.com/insight/effective-leadership-talent-selectiontalent-development/. 
Appendix A

Extended Literature Review 


\section{APPENDIX A}

\section{Extended Literature Review}

Collegiate sport has become an extremely competitive domain. Within the past two decades, college athletics has continued to grow in popularity and in financial productivity (Eitzen \& Sage, 2003). As a result, many athletic departments are beginning to highlight the use of successful athletics teams as a viable option for maintaining fiscal status related to academics (e.g., enrollment) and the universities as a whole (e.g., campus improvement projects). While traditionally it has been the coaches of revenue-producing sports, such as men's basketball and football, who had to meet lofty expectations of success, a current trend in athletic departments is requiring most, if not all, athletic programs to increase their degree of success.

Since 1993-1994, the National Association of Collegiate Directors of Athletics (NACDA) has awarded the Learfield Sports Directors' Cup, which ranks each university and college based on the success of all its varsity sports programs (http://www.nacda.com). The Learfield Sports Directors' Cup highlights the desire for academic institutions to develop successful programs across all sports, not just the traditional revenue-producing sports (e.g., football, men's basketball). By building successful athletics programs, colleges and universities hope to increase student enrollment and university prestige (Letawsky, Schneider, Pedersen, \& Palmer, 2003; Toma \& Cross, 1998). Due to this increased pressure and desire of athletic departments to hold successful athletics teams, college coaches are under increasing pressure to assemble talented squads to ensure program success over time. Thus, a vital aspect of college coaching, and one that is directly related to a program's success, is effectively identifying and recruiting talent. 
While effective recruiting can increase the likelihood of success, mistakes and miscues in recruiting have the ability to limit future success and can have a significant negative impact on the program which erred (Abbott \& Collins, 2004; Warren, 1997). This last point raises the following question: If recruiting is a vital component to a college program's success, how do coaches identify "talent" and which characteristics do coaches look for in potential athletes? While research exists in talent identification and development in youth athletes (Abbott \& Collins, 2004; Elferink-Gemser, Visscher, \& Lemmink, n.d.), there remains to be a gap when examining college coaches and recruiting/talent identification. Although recruiting appears to be an essential component of collegiate sport, limited research exists to explain or highlight the specific strategies and philosophies college coaches employ when making decisions regarding recruiting. Moreover, specific psychological skills and characteristics coaches look for has received limited attention as well, and it has not yet been determined if psychological characteristics play a factor in college recruiting.

\section{Talent Identification}

While recruiting collegiate athletic talent has garnered limited research attention, there has been an abundance of literature outlining the more popular concept of talent identification (TID) (Abbott \& Collins, 2004; Elferink-Gemser, Visscher, Lemmink, \& Mulder, 2007; Falk, Lidor, Lander, \& Lang, 2004; Johnson, Castillo, Sacks, Cavazos, Edmonds, \& Tenenbaum, 2008; Martindale, Collins, \& Daubney, 2005; Morris, 2000; Vaeyens, Lenoir, Williams, \& Philippaerts, 2008; Wolfenden \& Holt, 2005). Talent identification (TID) has been defined as the procedure of recognizing participants with the potential to excel in a particular sport (Vaeyens, Lenoir, Williams, \& Philippaerts, 2008). Several authors have postulated the importance of identifying talent and subsequent success of athletic organizations. Specifically, 
Martindale and Collins (2007) recognized the potential for an effective TID program to assist in the sustainment of elite sport organizations and enhance the financial rewards and prestige associated with a successful athletic organization. Furthermore, Morris (2000) highlights that successful prediction of athletic achievement would give a significant competitive advantage to any such sport organization that has this ability.

Many authors have proposed methods of identifying talent and the skills associated with successful and less successful athletes (Elferink-Gemser, Visscher, Lemmink, \& Mulder, 2007; Falk, Lidor, Lander, \& Lang, 2004; Johnson, Castillo, Sacks, Cavazos, Edmonds, \& Tenenbaum, 2008; Nieuwenhuis, Spamer, \& Van Rossum, 2002; Reilly, Bangsbo, \& Franks, 2000; Reilly, Williams, Nevill, \& Franks, 2000). For instance, Falk, Lander, and Lang (2004) studied 14-15 year old male water-polo players to identify various attributes that may assist in the selection process. Participants, over a 2-year period, completed a series of tests, including motor ability, physical ability, and evaluation of game intelligence. Results showed that the players who were selected to represent the junior national water-polo team all scored superior on all tests of physical ability, motor ability, and game intelligence, as compared to scores of participants who were not selected.

In a similar manner, Nieuwenhuis, Spamer, and Van Rossum (2002) tested 14-15 year old field female hockey players on motor-physical, kinanthropometric, and psychological variables to determine which skills influence more and less successful performance. The results from this study demonstrated that more successful performers scored better than less successful performers on specific motor-physical and sport-specific components (endurance, 40-yard sprint, ball handling, accuracy), in addition to one sport psychological variable (motivation to achieve success). While not definitive in offering an accurate method of talent identification, these 
studies do offer a framework for the use of various testing procedures aimed towards distinguishing between more and less successful athletes.

In their study of coaches' perceptions of elite athletes and non-elite athletes, Johnson et al. (2006) found participants' differentiated between these two groups based on the following six categories: 1) intrapersonal, 2) interpersonal, 3) lifestyle, 4) training, 5) environment, and 6) the interaction among the first four categories within the context of the fifth. Through qualitative means, the authors found that the coaches interviewed differentiate elite and non-elite athletes based on skills related to intrapersonal (i.e., level of commitment, willingness to work hard, level of competitiveness), interpersonal (i.e., coach-athlete relationships), training (i.e., train with expert coaches), and environmental factors (i.e., access to adequate training facilities). While the authors found that certain traits differentiate between more/less successful performers, they recognized that there is not a definitive pathway for success. Rather, the process of talent identification and development is non-linear and non-congruent, and varies from athlete to athlete.

The aforementioned studies of talent identification suggest that while certain talent identification testing procedures and coaching evaluations of talent may prove useful in discerning talent, there has yet to be a reliable and effective method of accurately identifying talent. In this manner, even though TID research has produced a number of relevant findings related to the valuable usage of these strategies, most authors agree that an effective model of application does not currently exist (Abbott \& Collins, 2004; Durand-Bush \& Salmella, 2001; Hany, 1993; Matsudo, 1996; Regnier, Salmella, \& Russell, 1993). While a few authors have highlighted specific characteristics coaches deem as more important when evaluating recruits (Kimbrough \& Copeland, no date; Johnson et al., 2008; Stiel \& Schneider, 2006), there is 
currently no empirical research based on the specific strategies and philosophies college coaches employ in the recruiting process. Previous authors have focused their attention on the identification of talent for elite and national junior level competition (Falk, Lidor, Lander, \& Lang, 2004; Johnson et al., 2008; Nieuwenhuis, Spamer, \& Van Rossum, 2002; Reilly, Williams, Nevill, \& Franks, 2000), but no research has been conducted in the area of talent identification from junior sport competition to collegiate competition.

Given the current competitive nature of collegiate sport programs, having the ability to effectively evaluate and identify talented athletes based on all aspects of performance (physical, psychological, sociological, anthropometric, etc.) would appear to be a significant advantage for coaches to gain a competitive edge over their opponents. Accurate talent identification, or recruiting, methods would likely be helpful in limiting recruiting errors, which would ultimately enhance the quality of an athletic program and its longevity in collegiate competition. The lack of empirical evidence in this area suggests that we do not yet know how college coaches identify and evaluate talent. Understanding these procedures and concepts at the collegiate level may offer another perspective into the world of talent identification, which has up to this point been focused primarily on junior athletes. Still, TID has not been extended to the collegiate ranks. Rather, the abundance of literature has pertained to the youth levels of sport participation. Talent: A Multidisciplinary Approach.

Gone are the days of viewing talent under a unidimensional lens, in which authors such as Regnier, Salmella, and Russell (1993) described talent as based on a set of characteristics related to physical prowess. Currently, talent is seen as a multidimensional construct, where an athlete can make up for his/her physical shortcomings through other outlets, such as being “mentally tough" or exerting a high level of drive and determination (Abbott \& Collins, 2004). 
Elferink-Gemser, Visscher, Lemmink, and Mulder (2007) offered support to the multidisciplinary approach of talent identification, which involved the combination of technical, tactical, and psychological characteristics in distinguishing between elite and sub-elite performers. The authors identified 30 elite and 35 sub-elite youth athletes from a talent development program ranging in age from 12-16 years. Participants were measured once per year across a three year time span on several characteristics, such as body mass, stature, interval endurance capacity, peak shuttle sprint, motivation, confidence, and concentration. Results indicated that most elite athletes scored better than their sub-elite counterparts on performance characteristics by the age of 14 , and all elite participants performed better than sub-elite participants by age 16. The findings from this study suggest that performance characteristics which distinguish between elite and sub-elite athletes are not derived from a singular realm, but rather, several factors play a significant role in athletic performance (Elferink-Gemser, Visscher, Lemmink, \& Mulder).

Similarly, in a review of literature by Abbott and Collins (2004), determinants of elite performance were based on multidimensional aspects including anthropometric, physical, and psychological factors. The psychological aspects of performance the authors identified were related to personality and psychological skills (e.g., goal setting, imagery, and commitment), and it was stated that the role of psychology in performance is likely mediated by numerous other factors, including an athlete's body size, type, and genetic predisposition. Still, the authors contend that talent identification literature may need to focus more attention on the role of psychological factors in the identification of athletic talent, rather than rely on physical and anthropometric features. The Elferink and colleagues (2007) and Abbott and Collins studies 
underscore the impact of multiple variables on elite performance and the role of both physical and psychological skills in performance success.

Other authors have identified similar aspects of the measurement and evaluation process of talent identification, which includes physiological, psychological, and sociological (Brown, 2001; Fisher \& Borms, 1990; Kimbrough \& Copeland, n.d.; Kulina, 2009). Brown (2001) described in length various physical skills important for a variety of sports, which included power, size, agility, and speed. Moreover, Brown illustrated the influence of extraneous variables that not all athletes possess, such as making teammates better players, sport anticipation, coachability, and having a "killer instinct." Additional authors have identified the role of these extra "factors" that separate certain athletes from others (Conley, 2009; Spoon, n.d.). Similarly, Kulina (2009) discussed the major characteristics college coaches look for in recruits, which he breaks into the categories of physical, psychological/intangibles, technical, and tactical.

With the multidisciplinary approach in mind, other authors have attempted to clarify the impact of specific physical and psychological factors on athletic success. Many authors have noted that, once at the elite level, it appears that physical and anthropometric variables do not play an important role in demarcating between more and less successful performers (Franks, Williams, Reilly, \& Nevill, 1999; Gabbett, Georgieff, \& Domrow, 2007; Reilly, Bangsbo, \& Franks, 2000), whereas psychological factors appear to differentiate performance success (Abbott \& Collins, 2004; Durand-Bush \& Salmella, 2001; Gould, Greenleaf, Dieffenbach, Chung, \& Peterson, 1999; Gould, Weiss, \& Weinberg, 1981; Williams \& Krane, 2001). In their in-depth review of anthropometric and physiological characteristics on elite soccer success, Reilly, Bangsbo, and Franks (2000) determined that it is not possible to separate 
individual characteristics for elite success with any assurance. The authors do highlight the importance of the possession of certain levels of aerobic and anaerobic power, agility, flexibility, and muscular development for athletic success, but recognized that differences in these skills are negligible at the elite level. In a similar fashion, Gabbett, Georgieff, and Domrow (2007) studied successful and unsuccessful junior volleyball players and found that physiological and anthropometric data did not discriminate between more and less successful performers. Rather, the discriminating factor was the coaches' subjective evaluation of skill tests (i.e., passing technique, serving technique).

The fact that the physical and anthropometric variables of the multidisciplinary approach many authors have identified are not indicative of separating elite and sub-elite performers may suggest that psychological composition may play an integral role in delineating elite performance, more so than previous researchers have suggested. While limited research currently exists in describing the role of psychology in elite performance, the lack of clarity in this area is a major factor as to why the current investigators are focused on the role of psychological factors in collegiate recruiting.

Talent Identification: Using the Multidisciplinary Approach as a Framework for Recruiting

While recruiting behaviors and approaches among collegiate coaches have not been identified, the oft studied concept of talent identification may proffer a foundation for reviewing college recruiting and the subjective and objective techniques associated with the evaluation phase of recruiting. Although there is no research to support this assumption, it is unlikely that coaches approach recruiting from a one-dimensional mindset, but rather take multiple factors into consideration (i.e., physical ability, attitude, interview data). Exploring the nature of college coaches' recruiting processes is needed to understand how future recruits are determined and 
how talent is "identified." With this in mind, no empirical research has focused on the specific strategies coaches employ. However, there is limited anecdotal evidence which suggests that coaches utilize a similar approach to talent identification as outlined by the multidisciplinary approach (Kimbrough \& Copeland, n.d.; Stier \& Schneider, 2006).

Kimbrough and Copeland (n.d.) surveyed 197 collegiate basketball coaches to determine which characteristics of recruits coaches rank as the most important. The authors developed 24 characteristics, which were grouped into six categories: 1) technical skills, 2) skill-related fitness abilities, 3) size and intensity, 4) intangibles, 5) cognitive abilities, and 6) experience and demographics. Participants ranked each category on a Likert scale ranging from 1 ("very important") to 4 ("least important"). Results highlighted the following skills as most important; shooting (technical skills), jumping ability (skill-related fitness), competitiveness (size and intensity), attitude (intangibles), self-discipline (cognitive abilities), and level of competition faced in high school (experience and demographics). The results from this study suggest that coaches take into account a multitude of factors and deem certain skills/traits as more important than others when recruiting athletes.

Similarly, Stier and Schneider (2006) studied the preferred player characteristics and skills of Division I basketball coaches. The authors collected survey data from 118 Division I men's basketball coaches. Participants were asked to respond to a 36-item, five-point Likert scale survey that included items related to work ethic characteristics, athletic skills, and other talents that might impact an athlete's likelihood of success or failure. The results showed that $74.6 \%$ of coaches rated "training hard" a 5 out of 5 ("very essential"), in addition to being the single most essential characteristic for winning. The remaining $25.4 \%$ of coaches rated this skill a 4 out of 5 ("essential"). Other pertinent findings showed that over half of the coaches surveyed 
rated the following skills the highest; strength and conditioning (72.9\%), player effort (64.4\%), game performance $(83.1 \%)$, team-oriented play (67.8\%), physical energy $(66.1 \%)$, defensive play (57.6\%), and passing skills (55.5\%). As was highlighted in the Kimbrough and Copeland (n.d.) article, this study lends support to the notion that coaches prefer certain characteristics over others, in addition to coaches viewing a variety of skills as important to an athlete's composition.

A number of anecdotal references have been made to the multidisciplinary concepts mentioned previously. Spoon (n.d.) listed traits NCAA coaches find desirable, including success, potential, versatility, leadership, work ethic/dedication, and personality/enthusiasm. The author refers to success as the accomplishments and national recognition the athlete has achieved prior to college and potential as the recruit's year to year progress that may indicate his/her future talent. Related to the intangibles athletes exude, leadership traits were highlighted as important from coaches' perspectives, as leaders have the capabilities of improving the team through "hard work, team focus, and a contagious desire to improve personally and collectively" (p. 2). Other intangible factors Spoon identified, work ethic and enthusiasm, generate support to the influence of a multitude of factors, while not relying solely on physical traits recruits possess.

\section{A Multidisciplinary Approach to Recruiting.}

In relation to recruiting, coaches appear to implement a multidisciplinary approach in that they consider physical prowess (Brown, 2001; Humara, 2000; Morris, 2000; Singer, 1972; Trninic, Papic, Trninic, \& Vukicevic, 2008; Tutko \& Richards, 1972), anthropometry (Franks, Williams, Reilly, \& Nevill, 1999; Gabbett, Georgieff, \& Domrow, 2007; Reilly, Bangsbo, \& Franks, 2000), and psychological skills (Connaughton, Wadey, Hanton, \& Jones, 2008; Gould, Dieffenbach, \& Moffett, 2002; Greenleaf, Gould, \& Dieffenbach, 2001; Jones, Hanton, \& Connaughton, 2002; Jones, Hanton, \& Connaughton, 2007; Smith, Schultz, Smoll, \& Ptacek, 
1995). However, the multidisciplinary approach to recruiting coaches utilize may lack the psychosocial component certain authors have identified in talent identification literature (Abbott \& Collins, 2004; Gould, Greenleaf, Dieffenbach, Chung, \& Peterson, 1999; Williams \& Krane, 2001). Further, while several authors have identified the importance of psychological skills from elite coaches' perspectives (Brown, 2001; Gould, Hodge, Peterson, \& Petlichkoff, 1987; Johnson et al., 2008; Tutko \& Richards, 1972), there currently exists no empirical evidence as to how these skills are determined, nor which skills are preferred and why. Understanding how elite coaches delineate between relevant and irrelevant psychological characteristics would offer deeper insight into the overall recruiting methods coaches employ when evaluating athletes; specifically, to what extent, if any, coaches use their assessment of a recruit's psychological attributes in the final decision making process.

Psychological Characteristics: Distinguishing Between More \& Less Successful Athletes

Since psychological characteristics are one specific component of talent identification (Brown, 2001; Warren, 1997), it is important to gain an understanding of how these characteristics may impact and influence athletic performance, as this may offer insight into the recruitment of certain athletes over others. While there is no research pertaining to the specific topic of collegiate recruiting and the influence of psychological characteristics, there is an abundance of literature which equates the existence of specific psychological skills and characteristics to that of more successful performers. In particular, researchers have identified the role of personality characteristics and psychological skills in distinguishing between more and less successful athletes.

Personality characteristics. For decades, researchers have attempted to connect psychological and personality characteristics to athletic success, especially for elite performers 
(Alderman, 1974; Cooper, 1969; Ogilvie, 1976; Van den Auweele, De Cuyper, Van Mele, \& Rzewnicki, 1993; Vealey, 1992). Morgan $(1978,1980)$ is credited with some of the earliest research in this area, utilizing the Profile of Mood States (POMS) to identify specific characteristics of elite athletes. Findings from Morgan's research led to the development of the iceberg profile model, which postulated that more successful athletes exhibited greater mental health than that of less successful athletes. Specifically, more successful athletes were found to exhibit higher levels of vigor and lower levels of negative moods (e.g., depression, anger, tension, fatigue, and confusion).

To date, research attempting to correlate personality and elite performance has been inconclusive and ambiguous at best (Rowley, Landers, Kyllo, \& Etnier, 1995; Van den Auweele et al., 1993). However, several authors have found that the use of specific psychological skills (e.g., goal setting, imagery) can offer psychological determinants of successful performance (Abbott \& Collins, 2004; Gould, Dieffenbach, \& Moffett, 2002; Jones, Hanton, \& Connaughton, 2002; Jones, Hanton, \& Connaughton, 2007; Mahoney, Gabriel, \& Perkins, 1987; Smith \& Christensen, 1994). Jones, Hanton, and Connaughton (2002) interviewed elite international performers and found common psychological themes among these athletes. Specifically, the mental attributes identified were categorized into general categories; self-belief, desire and motivation, focus, coping with competitive pressure and anxiety, and coping with physical and emotional pain.

Psychological skills. A number of researchers have examined how particular psychological variables and mental skills impact elite sport performance (Connaughton, Wadey, Hanton, \& Jones, 2008; Gould, Dieffenbach, \& Moffett, 2002; Gould, Weiss, \& Weinberg, 1981; Greenleaf, Gould, \& Dieffenbach, 2001; Jones, Hanton, \& Connaughton, 2002; Jones, Hanton, \& 
Connaughton, 2007; Mahoney \& Avener, 1977; Orlick \& Partington, 1988; Smith, Schultz, Smoll, \& Ptacek, 1995; Williams \& Krane, 2001). Williams and Krane (2001) identified several psychological characteristics evident in elite performers, which included positive imagery and self-talk, high commitment, self-regulation of arousal, and enhanced focus and concentration. Furthermore, specific mental skills employed for peak performance were highlighted, including the use of competition plans, goal setting, arousal management, thought control, and coping strategies.

Some authors have taken a multidimensional approach to the conceptualization of psychological attributes and elite performance by interviewing various individuals involved with elite athletic success (Connaughton, Wadey, Hanton, \& Jones, 2008; Gould, Dieffenbach, \& Moffett, 2002; Jones, Hanton, \& Connaughton, 2002; Jones, Hanton, \& Connaughton, 2007). In an attempt to further clarify the definition of mental toughness and determine the attributes needed to be a mentally tough performer, Jones, Hanton, and Connaughton (2002) interviewed ten international performers who had represented their countries at an elite level of competition. Through in-depth interviews and focus groups, the authors identified 12 ranked attributes of mental toughness, such as having an unshakable self-belief in ability to achieve goals, bouncing back from performance set-backs, and having an unshakable self-belief in the possession of unique qualities that make one better than others. While the authors recognized that each of the 12 attributes is an important aspect of being a mentally tough performer, they propose that the ranking of these attributes suggests certain attributes may be more important than others.

In a comparable approach, Gould, Dieffenbach, and Moffett (2002) interviewed ten U.S Olympic champions, in addition to one of their coaches and a parent, guardian, or significant other. In addition to interviews, athletes were given a series of psychological inventories to 
determine psychological characteristics and their development in elite performers. Similarly to Jones et al., 12 psychological skills were identified, such as the ability to cope with and control anxiety, mental toughness/resiliency, a hard-work ethic, and coachability.

Jones, Hanton, and Connaughton (2007) extended their 2002 study to further develop an accurate definition of mental toughness and the essential attributes of this concept, in addition to developing a framework for which to understand psychological skills in elite athletes. Eight Olympic or world-class champions, three coaches, and four sport psychologists were interviewed. The resulting information validated the authors' previous definition of mental toughness and led to the inclusion of 30 psychological skills inherent in elite athletes, which were clustered into attitude/mindset, training, competition, and post-competition.

In a series of interviews of former U.S. Olympic champions, Greenleaf, Gould, and Dieffenbach (2001) found that athletes were able to identify a number of psychological skills in which these athletes felt positively impacted their performance. Included were having high levels of confidence and motivation, blocking out distractions, and elevated levels of commitment to excellence. Other authors found that the psychological skills which differentiated between the most successful Olympians (i.e., medalists, world champions) and those who did not meet their performance potential were a total commitment to pursuing excellence, daily goal setting and imagery usage, and ability to deal with distractions (Orlick \& Partington, 1988).

Outside of qualitative data used in identifying psychological skills of elite performers, other authors have taken a more quantitative approach. For instance Smith, Schultz, Smoll, and Ptacek (1995) developed the Athletic Coping Skills Inventory-28 (ACSI-28) to measure sportspecific psychological skills. The ACSI-28 has been utilized by some authors to validate the 
mental skills previously mentioned (Gould, Dieffenbach, \& Moffett, 2002). This validation offers additional support to the notion that specific psychological characteristics not only exist, but can also differentiate between more and less successful performers.

Mental toughness. Adding to the existing literature on psychological characteristics and elite performance is the concept of labeling these performers as "mentally tough." Research attention has focused on mental toughness due to its perceived relationship with successful sport performance (Crust, 2007). This relationship can be intriguing when one considers the potential impact on recruiting, as coaches may covet athletes who exhibit qualities characteristic of a mentally tough persona. Jones, Hanton, and Connaughton (2002) recognized that, while mental toughness is one of the most commonly used terms in the field of applied sport psychology, it is also one of the least understood.

Even though several studies have examined how to develop mentally tough athletes (Bull, Albinson, \& Shambrook, 1996; Connaughton, Wadey, Hanton, \& Jones, 2008; Goldberg, 1998; Loehr, 1995), there currently exists no universal definition. With this in mind, there are numerous definitions of mental toughness and the characteristics of this concept. For example, some authors define mental toughness as the ability to cope with or handle stress, pressure, and adversity (Goldberg, 1998; Gould, Hodge, Peterson, \& Petlichkoff, 1987), whereas others define mental toughness as possessing superior mental skills (Bull, Albinson, \& Shambrook, 1996). Gucciardi, Gordon, and Dimmock (2008) defined mental toughness as "the superior mental characteristics of those athletes who excel in both practice and competitive situations, while others fail” (p. 262). Taking on a more theoretical approach, Clough, Earle, and Sewell (2002) proposed four constructs in defining mental toughness; control (capacity to exert an influence in the situation in question), commitment (tendency to take an active role in events), 
challenge (perception of change as an opportunity to grow and develop), and confidence (strong sense of self-belief). As was previously mentioned, Jones et al., (2007) also categorized psychological skills into four dimensions (attitude/mindset, training, competition, and postcompetition), which made up a framework of viewing mental toughness.

Characteristics associated with mental toughness have also been wide-ranging and include the following: high levels of confidence, self-belief, and self-esteem (Bull et al., 1996; Favret \& Benzel, 1997; Goldberg, 1998; Jones, Hanton, \& Connaughton, 2002; Thelwell, Weston, \& Greenlees, 2005; Woods, Hocton, \& Desmond, 1995); desire and commitment (Bull et al., 1996; Goldberg, 1998; Jones, Hanton, \& Connaughton, 2002; Thelwell, Weston, \& Greenlees, 2005); control, motivation, and achieving consistency (Gould et al., 1987; Graham \& Yocom, 1990; Thelwell, Weston, \& Greenlees, 2005); and effectively coping with pressure and distractions (Bull, Shambrook, James, \& Brooks, 2005; Jones, Hanton, \& Connaughton, 2002).

While the definition and subsequent characteristics of mental toughness is unclear and ambiguous, the term is widely used by sport psychologists, coaches, and athletes to denote a positive and preferable area of sport performance. As Gould et al. (1987) reported, 82\% of wrestling coaches rated mental toughness as the most important psychological attribute in determining the success of their athletes. Similarly, Weinberg and Gould (2007) assert that most coaches consider sport to be somewhere between 50-90\% mental when competing against others of similar ability. This suggests coaches must value, to some extent, the mental attributes of athletes and, as some authors have stated, may assist coaches in identifying individual strengths and weaknesses of their athletes (Leffingwell, Durand-Bush, Wurzberger, \& Cada, 2005). Identifying the Mentally Tough Athlete 
While there exists limited empirical research in the recruitment of athletes based on psychological characteristics, there is anecdotal support for the value of taking psychological skills into consideration. Tutko and Richards (1972) provided a methodological approach to evaluating psychological skills of opponents from a coaching perspective. Specifically, the authors highlight that "psychological scouting" includes focusing on players' behaviors before, during, and after competition. The authors highlight a plethora of traits or skills which can be solicited by watching players perform and interact with coaches, players, and officials. These traits include leadership qualities, coachability, emotional stability, self-confidence, toughness, drive, determination, aggression, anxiety, and rigidity.

Furthermore, Warren (1997) lists a number of psychological characteristics that make up a "quality player." Included in this list are players who: 1) have a willingness to work hard without question or complaint, 2) have a favorable attention span and concentration skills, 3) demonstrate leadership capabilities, and 4) enjoy competition and challenges. Adding to this list is Brown (2001) who categorizes essential mental and emotional skills into drive, passion, stability, positive attitude, realism, focus, effort, persistence, and competitiveness.

In his book "Sports Talent: How to Identify and Develop Outstanding Athletes", Brown (2001) touches on a common idiom used among sport coaches; intangibles. The author recognizes that coaches use the word "intangible" to denote some aspect of their players" makeup which cannot be ascertained by a quantitative measure. Brown argues that by intangibles, coaches are referring to the exhibition of extraneous traits few athletes possess, and when employed, drive performance to an even higher level.

Other authors have discussed the concept of intangibles and its role in recruiting. In an anecdotal account, Conley (2008) discussed the importance of factors external to physical talent: 
It's amazing, however, how often it's true that an abundance of physical talent doesn't translate to success on the gridiron. There are other factors -- the proverbial intangibles -which can indeed be the difference between being mediocre and being exceptional. Intangibles are the attributes an athlete possesses or the behavior he exhibits that require absolutely no physical talent but are crucial to success. These intangibles are sometimes difficult to measure, but any college coach will tell you they are worth their weight in gold. (p. 1)

Conley described four intangibles coaches look for in a recruit: 1) effort, 2) leadership, 3)attitude, and 4) intelligence. The author recognized that the vitally important factors (height, weight, speed, strength, etc.) certainly play a large role in a coach's evaluation, but the intangibles, which are not based on physical talents, are just as important. He explains that “...physical talents and skills are a huge part of the equation, but coaches are looking for the entire package in the young men they bring to campus. Often, the intangibles determine the true success of an individual and of a team" (p. 2).

Certain authors highlight the potential reality that coaches are inefficient in evaluating recruits' psychological characteristics which the coaches prefer. Humara (2000) states that, while coaches are experts in identifying physical traits and skills of athletes, they lack the ability to assess the psychological skills which impact sport performance. Although coaches may lack the ability to quantifiably assess psychological characteristics of recruits, it has been written in a number of anecdotal sources that athletes' psychological expressions during competition, practice, and interviews do influence a coach's perception of the capabilities of these athletes (Brown, 2001; Singer, 1972; Tutko \& Richards, 1972; Warren, 1997). The bridge between accurate evaluation of psychological skills in recruits and how coaches evaluate and base 
decisions off these evaluations remains unclear. Additionally, it remains to be unknown how effective coaches are in scouting psychological attributes of recruits and which skills are most influential.

\section{Conclusion}

With the continued escalation of competitiveness in collegiate sport, and the increased demands placed on coaches to recruit the best athletes, determining an efficient and accurate methodology of recruiting would appear to be pertinent to ensure continued success. Warren (1997) highlighted the impact successful athletics' programs can have on the overall financial status of universities and colleges, identifying several positive effects, such as increased enrollment and enhanced quality of applicants received. With this in mind, recruiting plays a critical role in the success or deterioration of a program. Some authors (Abbott \& Collins, 2004; Warren, 1997) found that recruiting errors can have a negative impact on a program, potentially over an extended period of time. Given the importance of successful recruiting, limiting mistakes in personnel selection would likely be top of mind for several coaches who strive to build or maintain a program's success during their tenure. However, the apparent importance of this topic has not been met with similar research attention to identify strategies or methods of accurate recruitment. While coaches have previously identified the importance of psychological skills in sport, there is limited research attention to suggest how coaches may assess these skills, and which skills coaches deem important.

Although it appears coaches consider a multitude of factors when recruiting, it is currently unknown if college coaches employ a specific recruiting philosophy, which includes how they evaluate potential recruits and which characteristics they prefer and why. Thus, there exists a need for research in this area for several reasons. First, the collegiate coaches' recruiting 
philosophies have received limited research attention to date. Furthermore, while an abundance of literature exists in the realm of talent identification and talent development among youth athletes (Abbott \& Collins, 2004; Falk, Lidor, Lander, \& Lang, 2004; Johnson, Castillo, Sacks, Cavazos, Edmonds, \& Tenenbaum, 2008; Martindale, Collins, \& Daubney, 2005; Morris, 2000; Vaeyens, Lenoir, Williams, \& Philippaerts, 2008; Wolfenden \& Holt, 2005), no research exists related to how these methods can be translated from youth to collegiate levels.

Second, while many authors have identified various psychological components that are related to athletic success (Abbott \& Collins, 2004; Elferink-Gemser, Visscher, \& Lemmink, 2007; Elferink-Gemser, Visscher, \& Mulder, 2004; Ericsson, Krampe, \& Tesch-Romer, 1993; Gould, Dieffenbach, \& Moffett, 2002), no research has studied whether coaches take psychological skills into consideration when recruiting.

Lastly, it is currently unclear if college coaches perceive psychological characteristics as important and if these characteristics influence recruiting decisions. Additionally, it is unknown which psychological characteristics are preferred and why these characteristics are desired. It is likely that by highlighting the recruiting philosophies of elite coaches who have proven track records of success, that these strategies will offer insight into the specific skill sets coaches desire and why they deem these skills important, all of which should be of interest to coaches and administrators alike. 


\section{References}

Abbott, A., \& Collins, D. (2004). Eliminating the dichotomy between theory and practice in talent identification and development: Considering the role of psychology. Journal of Sports Sciences, 22, 395-408.

Alderman, R. B. (1974). Psychological behavior in sport. Philadelphia: Saunders.

Brown, J. (2001). Sports talent: How to identify and develop outstanding athletes. Champlain, IL: Human Kinetics.

Bull, S. J., Albinson, J. G., \& Shambrook, C. J. (1996). The mental game plan: Getting psyched for sport. Eastbourne, UK: Sports Dynamics.

Bull, S. J., Shambrook, C. J., James, W., \& Brooks, J. E. (2005). Towards an understanding of mental toughness in elite English cricketers. Journal of Applied Sport Psychology, 17, 209-227.

Clough, P., Earle, K., \& Sewell. D. (2002). Mental toughness: The concept and its measurement. In I. Cockerill (Ed.), Solutions in sport psychology (pp.32-45). London: Thomson.

Conley, B. (2008, July). The importance of intangibles in recruiting. Retrieved April 2, 2009, from http://sports.espn.go.com/ncaa/recruiting/football/columns/story?columnist =conley_bill\&id=3499947.

Connaughton, D., Wadey, R., Hanton, S., \& Jones, G. (2008). The development and maintenance of mental toughness: Perceptions of elite performers. Journal of Sports Sciences, 26, 8395.

Cooper, L. (1969). Athletics, activity and personality: A review of the literature. Research Quarterly, 40, 17-22. 
Crust, L. (2007). Mental toughness in sport: A review. International Journal of Sport and Exercise Psychology, 5, 270-290.

Durand-Bush, N., \& Salmella, J. (2001). The development of talent in sport. In R. N. Singer, H.A. Hausenblas, \& C. M. Janelle (Eds.), Handbook of Sport Psychology, $2^{\text {nd }}$ ed. (pp. 269-289). New York: Wiley.

Eitzen, S.D. \& Sage, G.W. (2003). Sociology of North American Sport (7 $7^{\text {th }}$ Ed.). Dubuque, IA: William C. Brown/McGraw-Hill.

Elferink-Gemser, M. T., Visscher, C., Lemmink, K., \& Mulder, T. W., (2004). Relation between multidimensional performance characteristics and level of performance in talented youth field hockey players. Journal of Sports Sciences, 22, 1053-1063.

Elferink-Gemser, M. T., Visscher, C., Lemmink, K., \& Mulder, T. W., (2007). Multidimensional performance characteristics and standard of performance in talented youth field hockey players: A longitudinal study. Journal of Sports Sciences, 25, 481-489.

Ericcson, K. A., Krampe, R. T., \& Tesch-Romer, C. (1993). The role of deliberate practice in the acquisition of expert performance. Psychological Review, 100, 363-406.

Falk, B., Lidor, R., Lander, Y., \& Lang, B. (2004). Talent identification and early development of elite water-polo players: A 2-year follow-up study. Journal of Sports Sciences, 22, 347-355.

Favret, B., \& Benzel, D. (1997). Complete guide to water skiing. Champaign, IL: Human Kinetics.

Fisher, R. J., \& Borms, J. (1990). The search for sporting excellence. Schorndorf: Verlag Karl Hofman. 
Franks, A., Williams, A. M., Reilly, T., \& Nevill, A. (1999). Talent identification in elite youth soccer players: Physical and physiological characteristics. Journal of Sports Sciences, 17, 812.

Gabbett, T., Georgieff, B., \& Domrow, N. (2007). The use of physiological, anthropometric, and skill data to predict selection in a talent-identified junior volleyball squad. Journal of Sports Sciences, 25, 1337-1344.

Glaser, B. G., \& Strauss, A. L. (1967). The discovery of grounded theory: Strategies for qualitative research. Chicago: Aldine Publishing Company.

Goldberg, A. S. (1998). Sports slump busting: 10 steps to mental toughness and peak performance. Champaign, IL: Human Kinetics.

Gould, D., Dieffenbach, K., \& Moffett, A. (2002). Psychological characteristics and their development in Olympic champions. Journal of Applied Sport Psychology, 14, 172-204.

Gould, D., Greenleaf, C., Dieffenbach, K., Chung, Y., \& Peterson, K. (1999). Positive and negative factors influencing U.S. Olympic athlete and coaches: Nagano Games assessment (U.S. Olympic Committee Sport Science and Technology Final Grant Report, Colorado Springs, CO). Unpublished manuscript.

Gould, D., Hodge, K., Peterson, K., \& Petlichkoff, L. (1987). Psychological foundations of coaching: Similarities and differences among intercollegiate wrestling coaches. The Sport Psychologist, 1, 293-308.

Gould, D., Weiss, M., \& Weinberg, R. S. (1981). Psychological characteristics of successful and nonsucessful Big Ten wrestlers. Journal of Sport Psychology, 3, 69-81.

Graham, D., \& Yocom, G. (1990). Mental toughness training for golf. Lexington, MA: The Stephen Greene Press. 
Greenleaf, C. A., Gould, D., \& Dieffenbach, K. (2001). Factors influencing Olympic performance: Interviews with Atlanta and Nagano U.S. Olympians. Journal of Applied Sport Psychology, 13, 179-209.

Gucciardi, D. F., Gordon, S., \& Dimmock, J. A. (2008). Towards an understanding of mental toughness in Australian football. Journal of Applied Sport Psychology, 20, 261-281.

Hany, E. A. (1993). Methodological problems and issues concerning identification. In K.A. Heller, F. J. Monks, \& A. H. Passow (Eds.), International Handbook of Research and Developing of Giftedness and Talent (pp. 209-232). New York: Pergamon.

Humara, M. (2000). Personnel selection in athletic programs. Athletic Insight, 2 (2), 1-7.

Johnson, G. (2006). The Flutie effect. Retrieved February 28, 2009, from http://www.ncaa.org/wps/ncaa?ContentID=26168

Johnson, M. B., Castillo, Y., Sacks, D. N., Cavazos, Jr., J., Edmonds, W. A., \& Tenenbaum, G. (2008). "Hard work beats talent until talent decides to work hard": Coaches' perspectives regarding differentiating elite and non-elite swimmers. International Journals of Sports Science \& Coaching, 3, 417-430.

Jones, G., Hanton, S., \& Connaughton, D. (2002). What is this thing called mental toughness? An investigation of elite sport performers. Journal of Applied Sport Psychology, 14, 205218.

Jones, G., Hanton, S., \& Connaughton, D. (2007). A framework of mental toughness in the world's best performers. The Sport Psychologist, 21, 243-264.

Kimbrough, S., \& Copeland, J. (no date). The latest on collegiate recruiting: What qualities are important to coaches? Retrieved on April 2, 2009 from http://www.powerbasketball.com/ 061020.html 
Kulina, K. (2009). What college coaches look for: Your link to colleges. Retrieved on November 9, 2009 from http://baseballfactory.com/blog/2009/03/what-college-coaches-look-for-pt2.html

Leffingwell, T., Durand-Bush, N., Wurzberger, D., \& Cada, P. (2005). Psychological assessment. In J. Taylor \& G. Wilson (Eds.), Applying sport psychology: Four perspectives (pp. 85-100). Champaign, IL: Human Kinetics.

Letawsky, N. R., Schneider, R. G., Pedersen, P. M., \& Palmer, C. J. (2003). Factors influencing the college selection process of student-athletes: Are their factors similar to non-athletes? College Student Journal, 37, 604-610.

Loehr, J. E. (1995). The new mental toughness training for sports. New York: Plume.

Lyle, J. (2002). Sports coaching concepts. New York: Routledge.

Mahoney, M. J., \& Avener, M. (1977). Psychology of the elite athlete: An exploratory study. Cognitive Therapy and Research, 1, 135-142.

Mahoney, M. J., Gabriel, T. J., \& Perkins, T. S. (1987). Psychological skills and exceptional performance. The Sport Psychologist, 1, 181-199.

Martindale, R. J., Collins, D., \& Daubney, J. (2005). Talent development: A guide for practice and research within sport. Quest, 57, 353-375.

Matsudo, V. K. R. (1996). Prediction of future excellence. In O. Bar-Or (Ed.), The Child and Adolescent Athlete (pp. 92-108). Berlin: Blackwell Science.

Morgan, W. P. (1978). Sport personality: The credulous-skeptical argument in perspective. In W. F. Straub (Ed.), Sport psychology: An analysis of athlete behavior (pp. 330-339). Ithaca, NY: Mouvement. 
Morgan, W. P. (1980). The trait psychology controversy. Research Quarterly for Exercise and Sport, 51, 50-76.

Morris, T. (2000). Psychological characteristics and talent identification in soccer. Journal of Sports Sciences, 18, 715-726.

Nash, C. S., Sproule, J., \& Horton, P. (2008). Sport coaches’ perceived role frames and philosophies. International Journal of Sports Science \& Coaching, 3, 539-554.

Nieuwenhuis, C. F., Spamer, E. J., \& Van Rossum, J. (2002). Prediction function for identifying talent in 14- to 15-year old female field hockey players. High Ability Studies, 13, 21-33.

Ogilvie, B. (1976). Psychological consistencies within the personality of high-level competitors. In A. C. Fisher (Ed.), Psychology of sport: Issues and insights (pp. 335-358). Palo Alto, CA: Mayfield.

Orlick, T. (1990). In pursuit of excellence: How to win in sport and life through mental training ( $2^{\text {nd }}$ ed.). Champaign, IL: Human Kinetics.

Orlick, T., \& Partington, J. (1988). Mental links to excellence. The Sport Psychologist, 2, 105130.

Patton, M. Q. (2002). Qualitative research \& evaluation methods ( $\left.{ }^{\mathrm{rd}} \mathrm{ed}.\right)$. Thousand Oaks, CA: Sage Publications, Inc.

philosophy. (2009). In Merriam-Webster Online Dictionary. Retrieved February 28, 2009, from http://www.merriam-webster.com/dictionary/philosophy

Pollio, H. R., Henley, T., \& Thompson, C. B. (1997). The phenomenology of everyday life. New York: Cambridge University Press. 
Regnier, G., Salmella, J., \& Russell, S. J. (1993). Talent detection and development in sport. In R. N. Singer, M. Murphey, \& L. K. Tennant (Eds.), Handbook of Research in Sport Psychology (pp. 290-313). New York: Macmillan.

Reilly, T., Bangsbo, J., \& Franks, A. (2000). Anthropometric and physiological predispositions for elite soccer. Journal of Sports Sciences, 18, 669-683.

Reilly, T., Williams, A. M., Nevill, A., \& Franks, A. (2000). A multidisciplinary approach to talent identification in soccer. Journal of Sports Sciences, 18, 695-702.

Reynolds, F. (2005). Developing a formal coaching philosophy. Coaches Report, 12, 10-12.

Rowley, A., Landers, D., Kyllo, L., \& Etnier, J. (1995). Does the iceberg profile discriminate between successful and less successful athletes? A meta-analysis. Journal of Sport and Exercise Psychology, 17, 185-199.

Simonton, D. K. (1999). Talent and its development: An emergenic and epigenetic model. Psychological Review, 106, 435-457.

Singer, R. (1972). Coaching, athletics, and psychology. New York: McGraw-Hill.

Smith, R. E., \& Christensen, D. S. (1994). Psychological skills as predictors of performance and survival in professional baseball. Journal of Sport and Exercise Psychology, 17, 379-415.

Smith, R. E., Schultz, R. W., Smoll, F. L., \& Ptacek, J. T. (1995). Development and validation of a multidimensional measure of sport specific psychological skills: The Athletic Coping Skills Inventory-28. Journal of Sport and Exercise Psychology, 17, 379-398.

Spoon, R. (n.d.). College recruiting advice: What coaches want in recruits. Retrieved April 2, 2009 from http://www.winnersdepot.com/recruiting-advice/college-recruiters.htm.

Stier, W. F., \& Schneider, R. C. (2006). Preferred player characteristics and skills of Division I men's basketball coaches. The Sport Journal, 9, unpaginated. 
Thelwell, R., Weston, N., \& Greenlees, I. (2005). Defining and understanding mental toughness within soccer. Journal of Applied Sport Psychology, 17, 326-332.

Thomas, S. P., \& Pollio, H. R. (2002). Listening to patients: A phenomenological approach to nursing research and practice. New York: Springer.

Toma, J. D., \& Cross, M. E. (1998). Intercollegiate athletics and student college choice:

Exploring the impact of championship seasons on undergraduate applications. Research in Higher Education, 39, 633-661.

Trninic, S., Papic, V., Trninic, V., \& Vukicevic, D. (2008). Player selection procedures in team sport games. Acta Kinesiologica, 2, 24-28.

Tutko, T. A., \& Richards, J. W. (1972). Psychology of coaching. Boston: Allyn and Bacon.

Vaeyens, R., Lenoir, M., Williams, M., \& Philippaerts, R. M. (2008). Talent identification and development programmes in sport. Sports Medicine, 38, 703-714.

Van Den Auweele, Y., De Cuyper, B., Van Mele, V., \& Rzewnicki, R. (1993). Elite performance and personality: From description and prediction to diagnosis and intervention. In R.S. Singer, M. Murphey, \& L.K. Tenant (Eds.), Handbook of research on sport psychology (pp. 257-289). New York: Macmillan.

Van Maanen, J. (1983). Reclaiming qualitative methods for organizational research. In J. Van Maanen (Ed.), Qualitative Methodology (pp. 115-128). London: Sage Publications.

Vealey, R. (1992). Personality and sport: A comprehensive view. In T.S. Horn (Ed.), Advances in sport psychology (pp. 25-29). Champaign, IL: Human Kinetics.

Vealey, R. (2005). Coaching for the inner edge. Morgantown, WV: Fitness Information Technology. 
Warren, W. (1997). Coaching and control: Controlling your program, your team, and your opponents. New Jersey: Prentice Hall.

Weinberg, R. S., \& Gould, D. (2007). Foundations of sport and exercise psychology. Champaign, IL: Human Kinetics.

Williams, J. M. (1993). Applied sport psychology: Personal growth to peak performance $\left(2^{\text {nd }}\right.$ ed.). Mountain View, CA: Mayfield.

Williams, J. M., \& Krane, V. (2001). Psychological characteristics of peak performance. J. M. Williams (Ed.), Applied sport psychology: Personal growth to peak performance $\left(4^{\text {th }}\right.$ ed., pp.137-147). Mountain View, CA: Mayfield.

Wolfenden, L. E., \& Holt, N. L. (2005). Talent development in elite junior tennis: Perceptions of players, parents, and coaches. Journal of Applied Sport Psychology, 17, 108-126.

Woods, R., Hocton, M., \& Desmond, R. (1995). Coaching tennis successfully. Champaign, IL: Human Kinetics. 
Appendix B

Interview Script 


\section{APPENDIX B}

\section{Interview Script}

Good morning/afternoon/evening, thank you for participating in this research study. The purpose of the study is to determine the recruiting strategies of collegiate men's tennis coaches. I would like to audiotape this interview in order to accurately represent what you say; may I have your permission to tape this interview? Before we begin I want to make sure you understand the following:

- Your participation is entirely voluntary and you have the option to stop the interview at any time.

- You do not have to answer every question.

Thank you again for your willingness to participate in this study.

1. Tell me about your background in tennis (playing experience, years coaching, coaching level, etc.).

2. Describe the "ideal" collegiate tennis player.

3. What skills do you feel every tennis player must have?

4. Describe the "ideal" recruit.

5. What do you look for in a recruit?

6. What factors influence the type of players you recruit?

7. What percentage of tennis do you feel is psychological compared to physical?

8. What does "mental toughness" mean to you?

9. Is mental toughness important to you? If so, how do you assess a recruit's mental toughness?

10. What psychological traits found in athletes are most important to you?

11. Have you ever not recruited an athlete because you felt he did not have the psychological skills needed to be successful in college tennis? If so, describe a time when psychological skills swayed your decision in favor of or against a recruit.

12. Would you recruit an athlete who does not have the tennis skills you desire, but makes up for this deficiency in other areas (intangibles - leadership, personality, etc.)? Why or why not? 
Appendix C

Participation Request Letter 


\author{
APPENDIX C \\ Participation Request Letter
}

\title{
Dear Participant,
}

This letter is a request for you to take part in a research project to determine Division I men's tennis coaches' recruiting philosophies. This project is being conducted by Brandyn Fisher, MS, a doctoral student in sport and exercise psychology at West Virginia University. If you choose to participate, you will be asked a series of questions related to the topic of interest in an interview lasting between 45-90 minutes. Your participation in this project is entirely voluntary and you reserve the right to discontinue participation in this study at any time. Additionally, you may skip any question that you do not wish to answer.

All interview data will be kept confidential by removing names and affiliations of the interviewee, as well as any references made to persons that would potentially identify the interviewee. West Virginia University's Institutional Review Board acknowledgement of this project is on file.

Thank you very much for your time. Should you have any questions about this letter or the research project, please feel free to contact Brandyn Fisher at (443)243-5598 or by e-mail at Brandyn.Fisher@mail.wvu.edu.

Thank you for your time and help with this project.

Sincerely,

Brandyn Fisher, MS 
Appendix D

Self-Interview 


\author{
Self-Interview \\ Primary Investigator \\ Brandyn Fisher
}

Interviewer:

Tell me about your background in tennis, such as playing experience, and years coaching.

Brandyn:

I got a late start in the sport, not starting until I was almost 14 years old. I played at an elite junior level before getting injured my senior year in high school. During graduate school at West Virginia University I served as a volunteer assistant coach for women's tennis for two years. After grad school, I took a job at Academia Sanchez-Casal in Florida where I was the head of mental conditioning and an academy tennis coach for two years. After Sanchez-Casal, I took a job with the Junior Tennis Champions Center outside of Washington, DC. I have been coaching professionally for five years and have worked with several nationally and internationally ranked junior tennis players.

Interviewer:

Describe the "ideal" collegiate tennis player.

\title{
Brandyn:
}

The ideal college tennis player needs to have a number of skill sets to be successful. First, he must have the physical skills to compete at a high level in college. For instance, he must possess a big serve and solid ground strokes that feature a defining aspect of his game. Fitness is also extremely important at the collegiate level where players are exposed to various game styles and the player's ability to physically maintain himself at a high level over a longer period of time is essential. Secondly, the player must have certain mental skills and characteristics to find success at this level. Players need to be able to focus, be open to coaching, rebound from mistakes and errors, handle pressure, be hardworking, and be able to deal with the stressors associated with college tennis. The demands placed on athletes at the collegiate level are much higher than what most junior players experience, so being able to adapt to these higher demands is also important. The fact that players are not really exposed to a team environment within junior tennis is another consideration to keep in mind. Players are no longer simply playing for themselves, but are now part of a team that wins and loses together. This added pressure can be difficult for junior players to deal with because they understand that the outcome of their own match impacts the greater good of the team. Lastly, players must possess a certain level of academic success. To remain eligible to play, athletes must show proficiency in the classroom, which is a major consideration taken by college coaches when they look at recruits. Basically, the player must have the entire package, which is tennis skill, personality/mental characteristics, and academic functioning. 


\section{Interviewer:}

What skills do you feel every tennis player must have?

Brandyn:

Tennis players must possess a high fitness level and demonstrate that they are capable of winning with whatever type of game they play. Related to both of these skill sets, players must be mentally tough and know how to effectively manage pressure and their emotions. Typically, successful players have shown through experience that they know how to win and how to handle themselves on the court.

Interviewer:

Describe the "ideal" recruit.

Brandyn:

The ideal recruit would possess the entire package, mental, physical, emotional, and academic. The player would have experience playing at the elite junior levels, as well as the lower stages of the professional ranks. Preferably, they would have plenty of experience competing against international players and the various game styles that exist. The recruit must be able to handle being a tennis player at an elite level, in addition to being a high level student. Further, the recruit should possess qualities that make the team better and add something to the mix in terms of team development and camaraderie.

Interviewer:

What do you look for in a recruit?

Brandyn:

I look at how they handle themselves when they compete, specifically when things are going poorly or at big moments in the match. I think you can see a lot from a player with how they react and handle the situation. Being able to handle adversity and the pressure is huge in college tennis, so seeing it at the junior level helps to shed light on how they might react in a collegiate setting. I also try to get a sense of a recruit's personality and how he may fit on a team. Relate to this, I attempt to assess their strengths and weaknesses as a player on the court and as a person off it.

Interviewer:

What factors influence the type of players you recruit?

Brandyn: 
I take both qualitative and quantitative information into consideration. This is based on what I see in person, what I hear from other people who know the recruit, and from the results I can view from tournaments and competition. The other quantitative information I look at is their academic level and what type of school they attend. With online and home schooling options becoming more and more popular it is difficult to get a true assessment of a recruit's academic abilities.

Interviewer:

What percentage of tennis do you feel is psychological compared to physical?

Brandyn:

I would say that tennis at the collegiate level is $75 \%$ psychological versus $25 \%$ physical. The physical component at this level still separates the elite versus the non-elite players, whereas at the professional level the mental component is more indicative of the separation between the two.

Interviewer:

What does "mental toughness" mean to you?

Brandyn:

Mental toughness is how a player is able to manage himself during training and competition, in addition to maintaining a high level of performance throughout the ups and downs. I think mental toughness is a considerable factor that separates players from one another and influences a player's ceiling capacity. Additionally, mental toughness is not restricted to competition, but also to every aspect of the player's sport, such as their preparation, ability to train at a high level, reaction to injury, and so forth.

Interviewer:

Is mental toughness important to you? If so, how do you assess a recruit's mental toughness?

Brandyn:

Of course mental toughness is important, as it certainly plays a role in a player's ability to be successful. Assessing these skills is difficult at best but I do think you can see when these skills are present. To be able to see trends in a player's behavior though the coach must be able to watch them perform across different situations and matches. It can be easy to make a poor evaluation of a player by simply seeing them compete once, whether it is a positive or a negative one. Without being able to watch a player compete firsthand it would be difficult to accurately assess his mental toughness. A coach's experience plays a large role in evaluating these skills. Through years of coaching, coaches develop a library if you will, in which they can recall former 
players and how their personalities and reactions to certain situations played a role in their longterm development and success.

Interviewer:

What psychological traits found in athletes are most important to you?

Brandyn:

Openness to coaching and ability to listen are very important, because without these traits it makes it difficult to communicate and truly help the player get better and learn from his strengths and weaknesses. Also, given that college coaches can coach during the matches, if the player does not listen then they may not be able to make necessary adjustments during competition. Other traits that are important are perseverance and passion. It is common for players to experience drops in performance and as a result may find themselves struggling to put the ball in the court. It can be tough for players to maintain their motivation and positive attitude when this happens, so being able to persevere in the face of adversity and when things aren't going well is important. Further, players must have passion and a true love of the game, because the season can be a grind. Without a genuine love of the game, players may lose their way and their performance may suffer. If players are passionate about playing then they are usually more focused, positive, and healthier mentally as a result.

Interviewer:

Have you ever not recruited an athlete because you felt he did not have the psychological skills needed to be successful in college tennis? If so, describe a time when psychological skills swayed your decision in favor of or against a recruit.

Brandyn:

Yes, we have passed on recruits due to our perception that they would not fit the mold of the type of player we needed to be successful. For instance, I was recruiting a player in Florida who I had never seen compete in person. The tipping point for me was how he handled himself during times of adversity throughout the match. By the end, he was not even running for balls or trying to compete. Even though this was the only time I ever saw him in person, that one instance was enough for me to scratch him off our list. We need guys we can trust to send out on the court and give their best. They do not always need to be the most athletic or skilled player, but wanting to fight to the end is essential.

Interviewer:

Would you recruit an athlete who does not have the tennis skills you desire, but makes up for this deficiency in other areas (intangibles - leadership, personality, etc.)? Why or why not?

Brandyn: 
Absolutely. Although it would be great to have a complete player and person who has all the skills both on and off the court, that is unrealistic. Each player on the team serves and provides a specific role, and only a handful of players will actually compete. The guys who are not in the starting lineup usually provide other necessary attributes to the team, such as work ethic and determination. There are plenty of examples of recruits we have sought after simply because they had great personal qualities that we thought would make the team better and more complete. 
Appendix E

Data Tree 
Appendix E

Data Tree

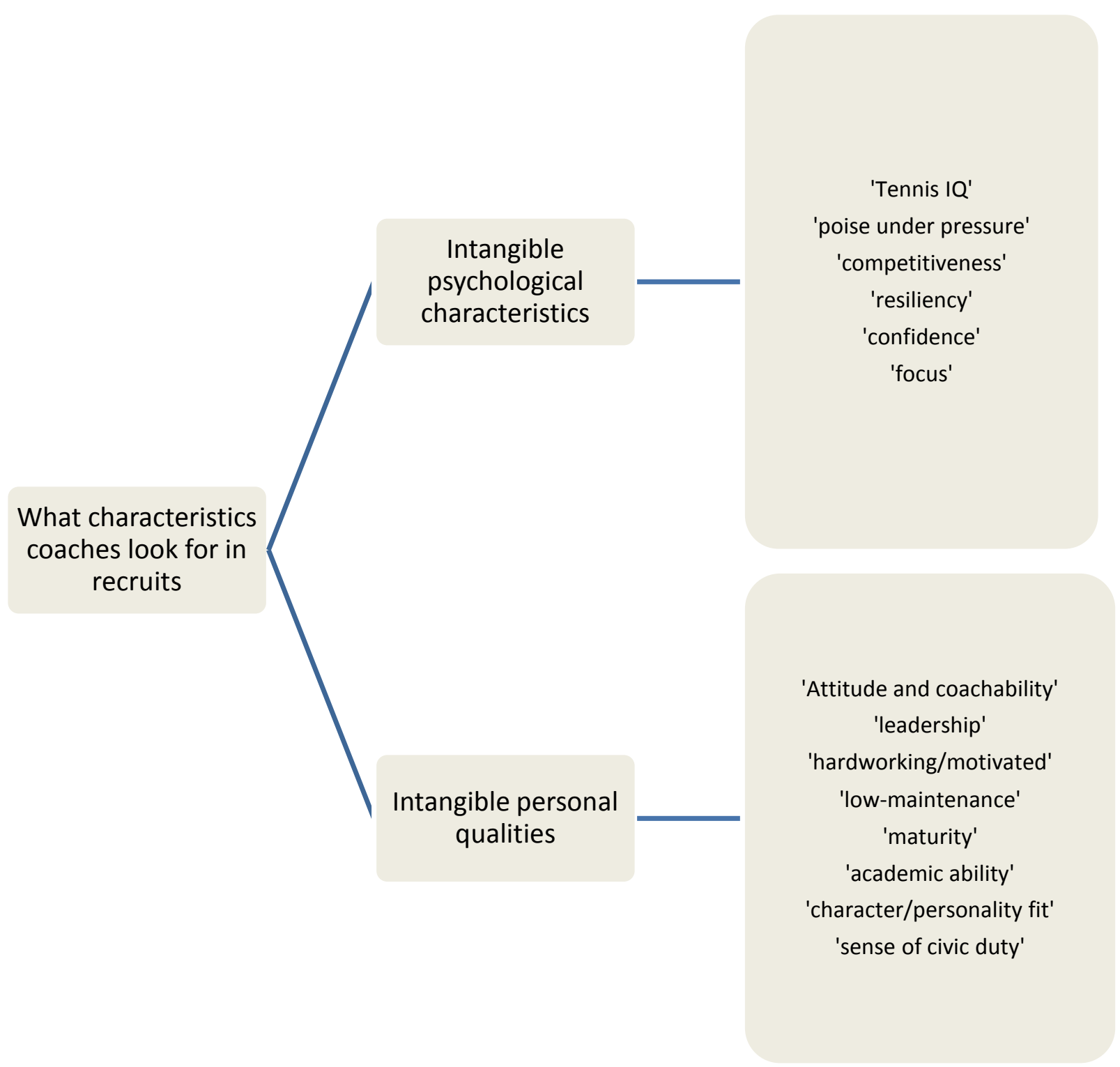




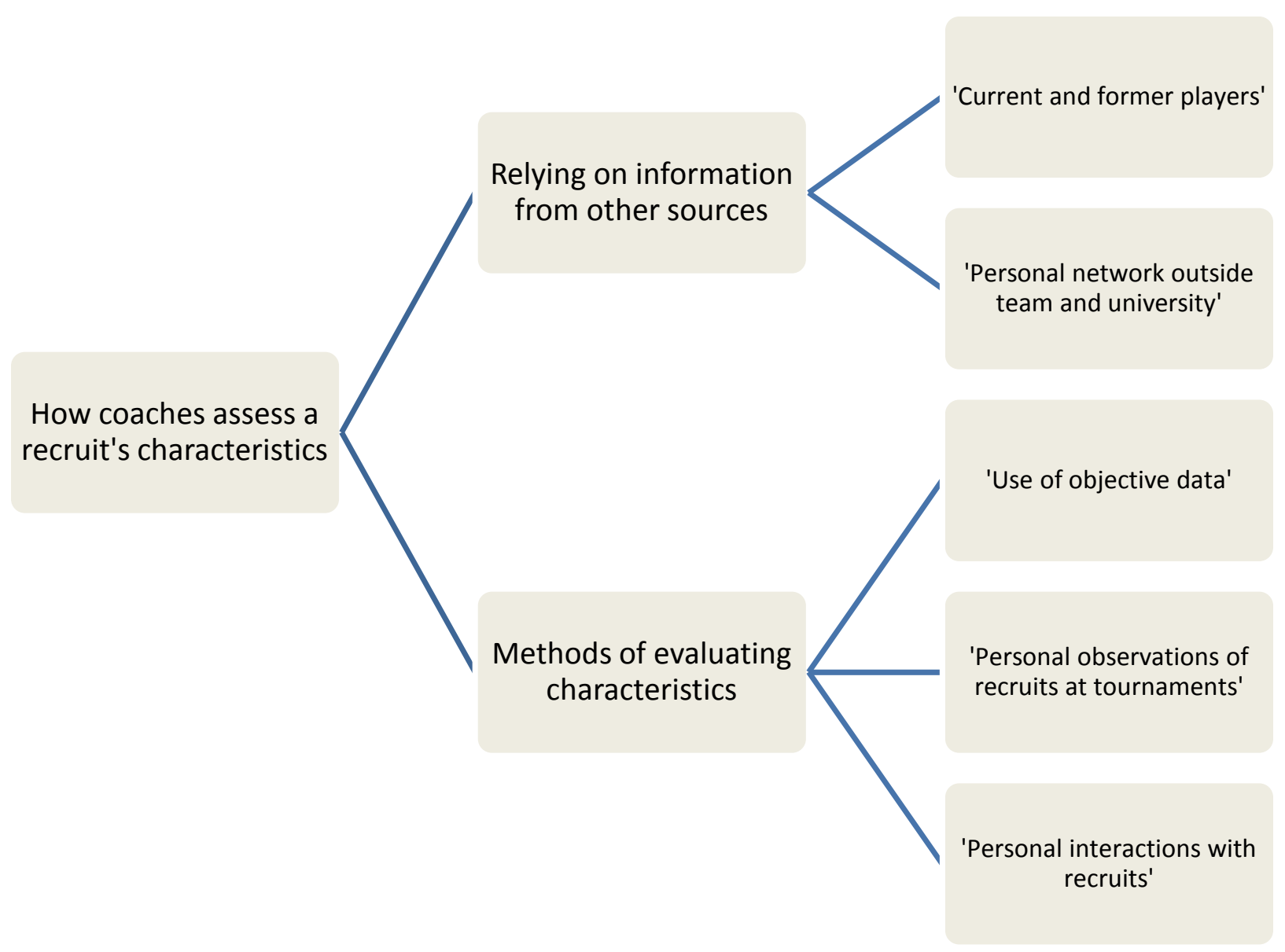

